Review article

\title{
Genetic polymorphisms in amyotrophic lateral sclerosis: Evidence for implication in detoxification pathways of environmental toxicants
}

\author{
Efthimios Dardiotis $^{\mathrm{a}, *, 1}$, Vasileios Siokas ${ }^{\mathrm{a}, 1}$, Maria Sokratous ${ }^{\mathrm{a}}$, Zisis Tsouris ${ }^{\mathrm{a}}$, \\ Amalia Michalopoulou $^{\mathrm{a}}$, Athina Andravizou ${ }^{\mathrm{a}}$, Metaxia Dastamani ${ }^{\mathrm{a}}$, Styliani Ralli ${ }^{\mathrm{a}}$, \\ Marco Vinceti $^{\mathrm{b}, \mathrm{c}}$, Aristidis Tsatsakis ${ }^{\mathrm{d}}$, Georgios M. Hadjigeorgiou ${ }^{\mathrm{a}}$ \\ a Department of Neurology, Laboratory of Neurogenetics, University of Thessaly, University Hospital of Larissa, Larissa, Greece \\ ${ }^{\mathrm{b}}$ Department of Biomedical, Metabolic, and Neural Sciences, University of Modena and Reggio Emilia, Modena, Italy \\ ${ }^{\mathrm{c}}$ Department of Epidemiology, Boston University School of Public Health, Boston, USA \\ ${ }^{\mathrm{d}}$ Laboratory of Toxicology, School of Medicine, University of Crete, 71003 Heraklion, Greece
}

\section{A R T I C L E I N F O}

Handling Editor: Robert Letcher

Keywords:

Amyotrophic lateral sclerosis

Pesticides

Heavy-metals

Gene-environmental interaction

SNPs

\begin{abstract}
A B S T R A C T
Amyotrophic lateral sclerosis (ALS) is a severe neurodegenerative disease of the central nervous system, characterized by progressive loss of motor neurons, and occurring in both sporadic and familial form. The origin of the disease is unknown, though increasing evidence suggests that the interaction between genetic and environmental factors may increase susceptibility to ALS, including its sporadic form. Although genetic mutations have been correlated to the familial type of ALS, relatively little is known about the sporadic type (sALS). Genetic factors concerning pesticide metabolism and heavy metal detoxification are increasing the susceptibility to sALS. This review focuses on the genes implicated in metabolic detoxification pathways of environmental toxicants and their potential role in ALS susceptibility.
\end{abstract}

\section{Introduction}

Amyotrophic lateral sclerosis (ALS) is a heterogeneous group of neurodegenerative disorders (Hardiman et al., 2017; Sabatelli et al., 2016). It is considered to be the third most common neurodegenerative disease and the most frequent form of motor neuron disease with onset in the adulthood (Renton et al., 2014). ALS is characterized by progressive loss of motor neurons and rapidly progressive paralysis (Appel et al., 2011). It remains a very serious health problem, as within 2 to 3 years after the first symptoms, respiratory failure leads to death (Rowland and Shneider, 2001). Despite the fact that the cause of ALS still remains unknown, accumulative evidence suggests that genetic and environmental factors may be involved and interact to increase the susceptibility to ALS development (Peters et al., 2015; Zarei et al., 2015).

At genetic level, ALS can be classified into familial ALS (fALS), which constitutes approximately $10 \%$ of all ALS cases and sporadic ALS (sALS), with no evident genetic linkage, which accounts for $90 \%$ of all ALS cases (Chen et al., 2013). Genetic mutations were found to be responsible for fALS under autosomal dominant, autosomal recessive or X-linked mode of inheritance (Chen et al., 2013; Renton et al., 2014;
Taylor et al., 2016). Recently, a considerable effort has been made in order to elucidate the genetic susceptibility of sALS. Candidate gene association studies (CGASs) and genome-wide association studies (GWASs) have led to the identification of several genetic loci that may modify the risk of sALS (Chen et al., 2013; Mitropoulos et al., 2017; Nicolas et al., 2018; Renton et al., 2014).

Quite a few exogenous factors such as smoking, antioxidants, physical exercise \& fitness, body mass index, electromagnetic fields, head trauma, metabolic and inflammatory diseases, viral infections, metals and pesticide exposure have been incriminated for possible contribution to ALS development (Ingre et al., 2015; Su et al., 2016; Vinceti et al., 2012). There is evidence that polymorphisms may modify the effect of environmental exposures to the risk of disease development (Kelada et al., 2003). The interplay between genetic and environmental factors and epigenetic modifications may have an impact on ALS susceptibility (Al-Chalabi and Hardiman, 2013; Paez-Colasante et al., 2015; Zarei et al., 2015; Zufiria et al., 2016). A few studies, with a variety in design (case-control, cohort, perspective, meta-analysis and systematic reviews) have demonstrated an association between ALS and pesticides, heavy metals, mercury and xenobiotics (Bozzoni et al., 2016; Capozzella et al., 2014; Deziel et al., 2015; Gibb and O'Leary, 2014;

\footnotetext{
* Corresponding author at: Department of Neurology, University Hospital of Larissa, Faculty of Medicine, University of Thessaly, Biopolis, Mezourlo Hill, Larissa 41100, Greece.

E-mail address: edar@med.uth.gr (E. Dardiotis).

${ }^{1}$ Equal contribution.
} 
Krewski et al., 2017; Yu et al., 2014). However, there are also studies that have failed to reveal any association (Capozzella et al., 2014; Vinceti et al., 2017a; Vinceti et al., 2017b; Yu et al., 2014). The review by Bozzoni et al. concluded that there is strong evidence that pesticides have a crucial role in ALS development and that they are significant risk factors for neurodegeneration (Bozzoni et al., 2016). In contrast, the meta-analysis by Capozzela et al. has failed to prove a strong correlation between exposure to pesticides and ALS risk, as only a mild association was revealed (Capozzella et al., 2014). Moreover, Kamel et al. have indicated that ALS risk may depend on the kind of the pesticide (Kamel et al., 2012). There is also accumulative body of epidemiologic evidence that long-term pesticide exposure (even in low doses) predisposes to several neurodegenerative diseases (Baltazar et al., 2014; Zaganas et al., 2013). Long term exposure to organochlorine and to organophosphate pesticides may have a crucial role in Motor neuron Disease development (Kanavouras et al., 2011). Regarding the role of heavy metals (selenium, mercury, cadmium and iron) in ALS, despite the large number of studies, only a few of them have revealed an association (Bozzoni et al., 2016; Trojsi et al., 2013; Vinceti et al., 2014). Additionally, both xenobiotic metabolism pathways and genetic variation, which affects xenobiotic metabolism, may confer susceptibility to ALS (Kasperaviciute et al., 2007).

It is possible that the divergence in findings regarding the effects of pesticide exposure, heavy metals and xenobiotic metabolism on ALS risk may result from the genetic variability among the studied populations. Pesticide to gene interaction has been demonstrated by genetic association studies as well as by animal models (Dardiotis et al., 2013b). The aim of the present review is to discuss the current knowledge by focusing on genes that predispose to ALS development and are probably implicated in toxicity mechanisms and detoxification metabolic pathways of environmental toxicants.

\section{Methods-study identification and selection}

We searched PubMed for peer-reviewed articles, published in English language through December 2017, concerning human studies on ALS and polymorphisms across genes that are implicated to detoxification pathways of environmental toxicants. Our search included "amyotrophic lateral sclerosis" and "polymorphisms", in combination with the following terms: "pesticides", "lead", "heavy metals", "iron", "toxicity" and "oxidative stress", as free words. Last literature search was performed on December 31st, 2017. Additionally, reference lists of all retrieved articles were examined in order to identify studies missing from our initial database search. Published studies (case-control candidate gene association studies, gene-environment studies, meta-analyses, genome wide association studies, mutational screenings, cases only studies) between 1996 and 2016 were included. Baseline characteristics from studies regarding PON1, PON2 and PON3 genes are summarized in Table 1. Baseline characteristics from studies regarding ALAD, VDR, SNCA, MT family genes, MTF-1, GSS, FMO, SOD1, HFE, PGC-1 $\alpha$, Nrf2, Transferrin, GSTs, ACHE, BCHE, NTE, FAH, CNR1, AADACL1, AFMID, APEH, CYP1A, CYP1B1, CYP2B6, CYP2C, CYP2D6, CYP2E1 and CYP3A are presented in Table 2.

\section{Results \& discussion}

\subsection{PON1, PON2 and PON3}

Paraoxonase-1 gene: Paraoxonase-1 (PON1) is a serum calcium dependent esterase enzyme that is synthesized primarily in the liver and carried by high density lipoproteins (HDLs) (Costa et al., 2013). Its main function is to catalyze hydrolysis of the active metabolites (oxons) of some organophosphates including parathion, diazinon and chlorpyrifos (Costa et al., 2013). Hydrolysis of these products leads to the metabolites: diethylphosphate (DEP), trichloropyridinol (TCP), methylpyrimidinol (MHP) and para-nitrophenol (PNP) (Androutsopoulos et al., 2011). Variants across PON1 gene have been reported to influence the concentration of paraoxonase- 1 enzyme in serum, the protein stability and/or its catalytic activity (Dardiotis et al., 2013b). Rs662 (Q192R) and rs854560 (L55M) are non-synonymous functional coding polymorphisms that affect PON1 expression, catalytic function and plasma levels (Adkins et al., 1993; Androutsopoulos et al., 2011; Dardiotis et al., 2013b). The isoform with arginine (R) at 192 breaks down paraoxon, while the isoform with glutamine (Q) at 192 is more efficient in breaking down sarin, diazozon and soman (Adkins et al., 1993; Androutsopoulos et al., 2011; Dardiotis et al., 2013b; Morahan et al., 2007b). The other functional polymorphism rs854560 (L55M) influences PON1 plasma levels (Adkins et al., 1993; Androutsopoulos et al., 2011; Dardiotis et al., 2013b; Morahan et al., 2007b). More precisely, individuals with methionine (M) at the position 55 reveal decreased expression, lower levels and reduced activity of PON1 (Adkins et al., 1993; Androutsopoulos et al., 2011; Dardiotis et al., 2013b; Morahan et al., 2007b). The 3D model of the PON1 normal and mutant proteins [resulting from rs662 (Q192R) and rs854560 (L55M)] based on SWISS-MODEL protein structure software (http://swissmodel. expasy.org/) and the main pathophysiology of the hydrolysis of chlorpyrifos-oxon, paraoxon and diazoxon by PON1 to DEP and other secondary metabolites are depicted in Fig. 1.

Rs662 (Q192R) and rs854560 (L55M) SNPs have also been associated with other neurodegenerative diseases, such as Alzheimer's disease (AD), Parkinson's disease (PD) and multiple sclerosis (MS) (Menini and Gugliucci, 2014). A recent meta-analysis also provides strong evidence that the PON1 rs705379 is associated with the risk of AD (Nie et al., 2017). However, the results of case-control studies and metaanalyses remain conflicting (Lee et al., 2015; Liu et al., 2012; Menini and Gugliucci, 2014; Pi et al., 2012; Wills et al., 2009; Zintzaras and Hadjigeorgiou, 2004). L55M and Q192R variants have been found to increase the risk of organophosphate toxicity in a population-dependent manner (You et al., 2013). Moreover, decreased PON1 activity has been associated with I102V PON1 polymorphism as well as with the risk alleles of the promoter polymorphisms rs705379 $(-108 \mathrm{~T}>\mathrm{C})$ and rs705381 ( $-162 \mathrm{G}>\mathrm{A}$ ) across the $5^{\prime}$ regulatory-region (Brophy et al., 2001; Cronin et al., 2007; Marchesani et al., 2003; Morahan et al., 2007b). These findings suggest a possible functional effect of the aforementioned SNPs across PON1.

Two case-control studies examined the possibility of increased ALS susceptibility among individuals with specific PON1 polymorphisms rendering them more vulnerable to the organophosphate-induced neurotoxic effects (Diekstra et al., 2009; Morahan et al., 2007b). Morahan et al. examined 143 sALS cases and 143 controls. Pesticide/herbicide exposure was estimated according to participants' self-reports. For the susceptibility allele, the following interactive effects were observed, regarding the risk of sALS as clinical endpoint: a) for the promoter polymorphisms $832 \mathrm{~g}>\mathrm{a},-162 \mathrm{~g}>\mathrm{a}$ and $-108 \mathrm{c}>\mathrm{t}$, when the exposed to pesticides group was compared to the non-exposed group, b) for Q192R, when the high-dose and no-exposed groups were compared and c) for the promoter polymorphisms (909g $>\mathrm{c}$, $-832 \mathrm{~g}>\mathrm{a},-162 \mathrm{~g}>\mathrm{a}$ and $-108 \mathrm{c}>\mathrm{t}$ ), when the low-dose and non-exposed groups were compared. However, no gene-environmental interactions were revealed by the genotype or haplotype levels or when the high-dose group was compared to the non-exposed one (with the exception of Q192R). Hence, the authors suggested that this effect is small and further analysis of other SNPs is of great necessity (Morahan et al., 2007b). In the case-control models of this study, T allele of $-108 \mathrm{c}>\mathrm{t}$ was overrepresented in sALS patients compared to controls. Moreover, a trend towards association with promoter haplotypes was observed. More precisely, haplotypes that decrease PON1 expression were associated with sALS, whereas haplotypes that increase PON1 expression were reported in controls (Morahan et al., 2007b). Diekstra et al. hypothesized that ALS patients living near agricultural fields would be more exposed to pesticides than those who live in urban areas. Therefore, they recruited 98 ALS patients in total (49 from urban 


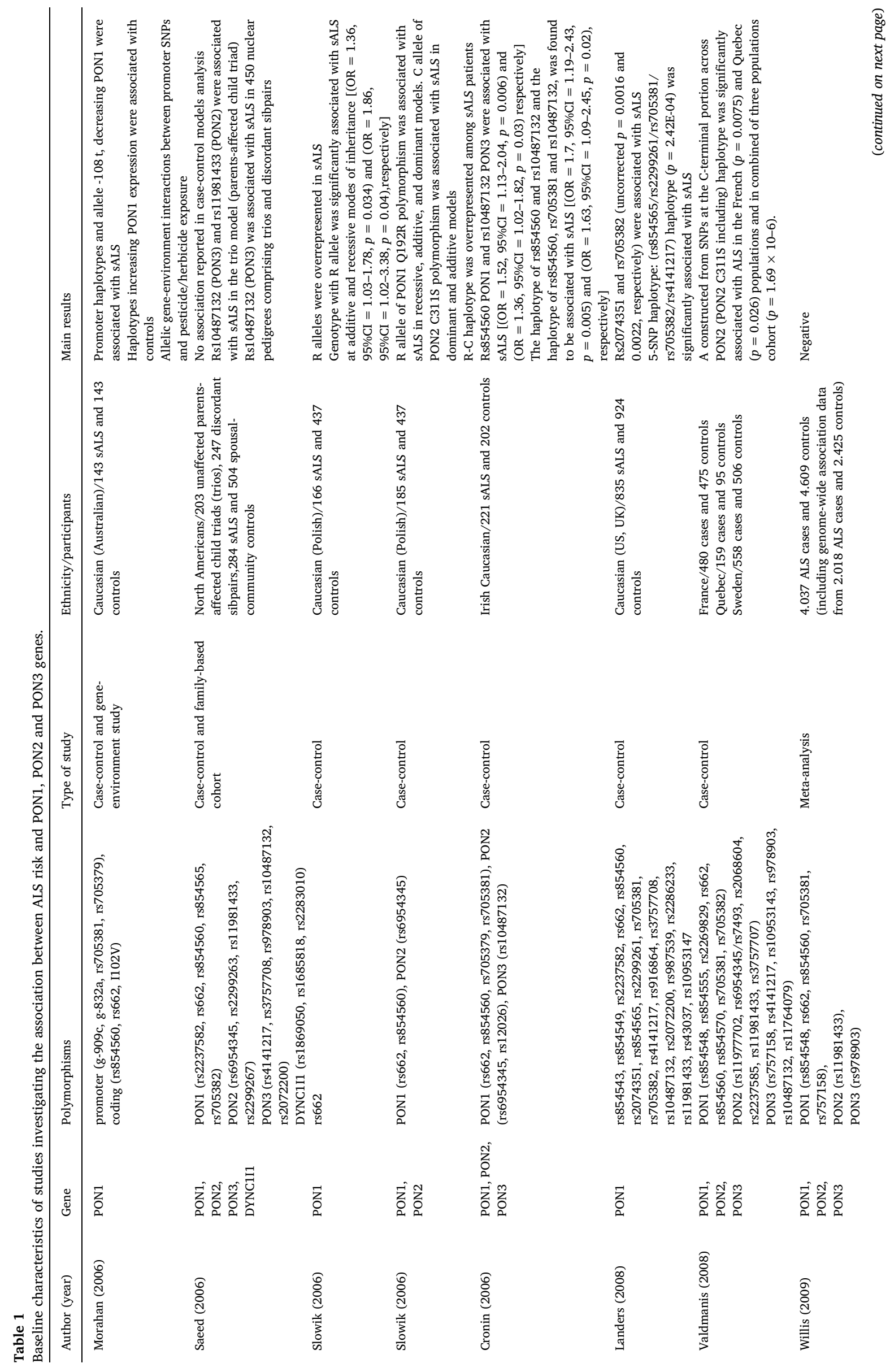




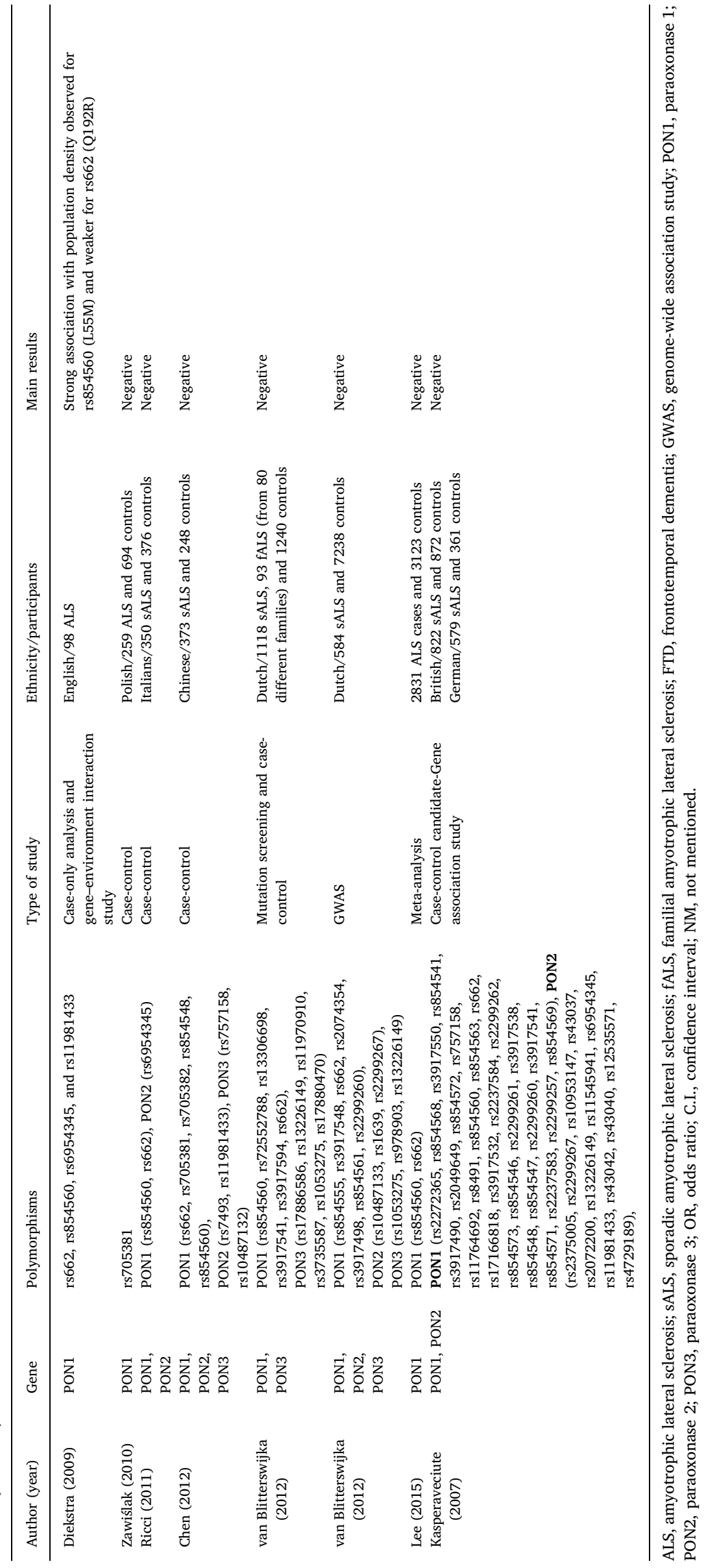




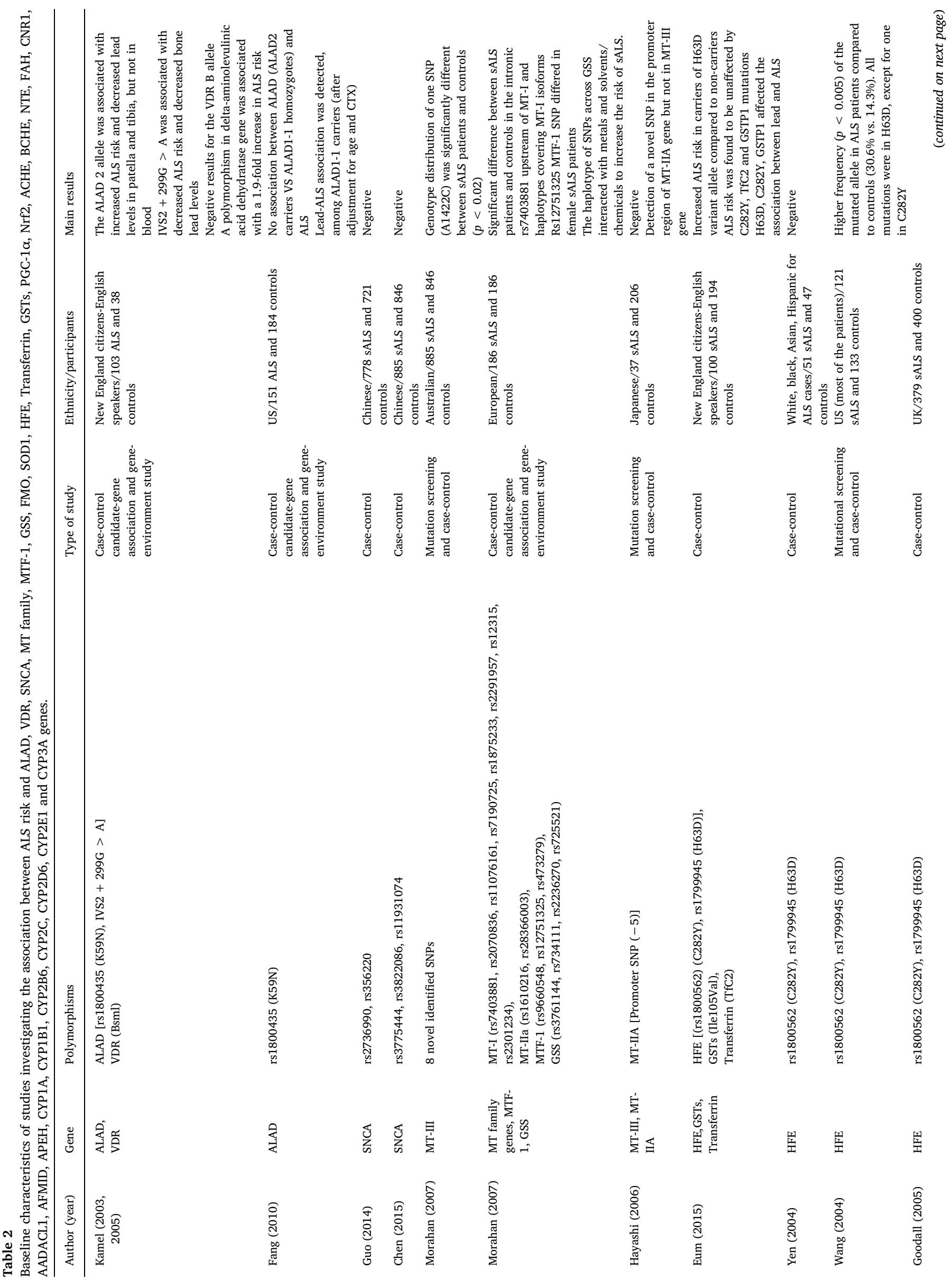




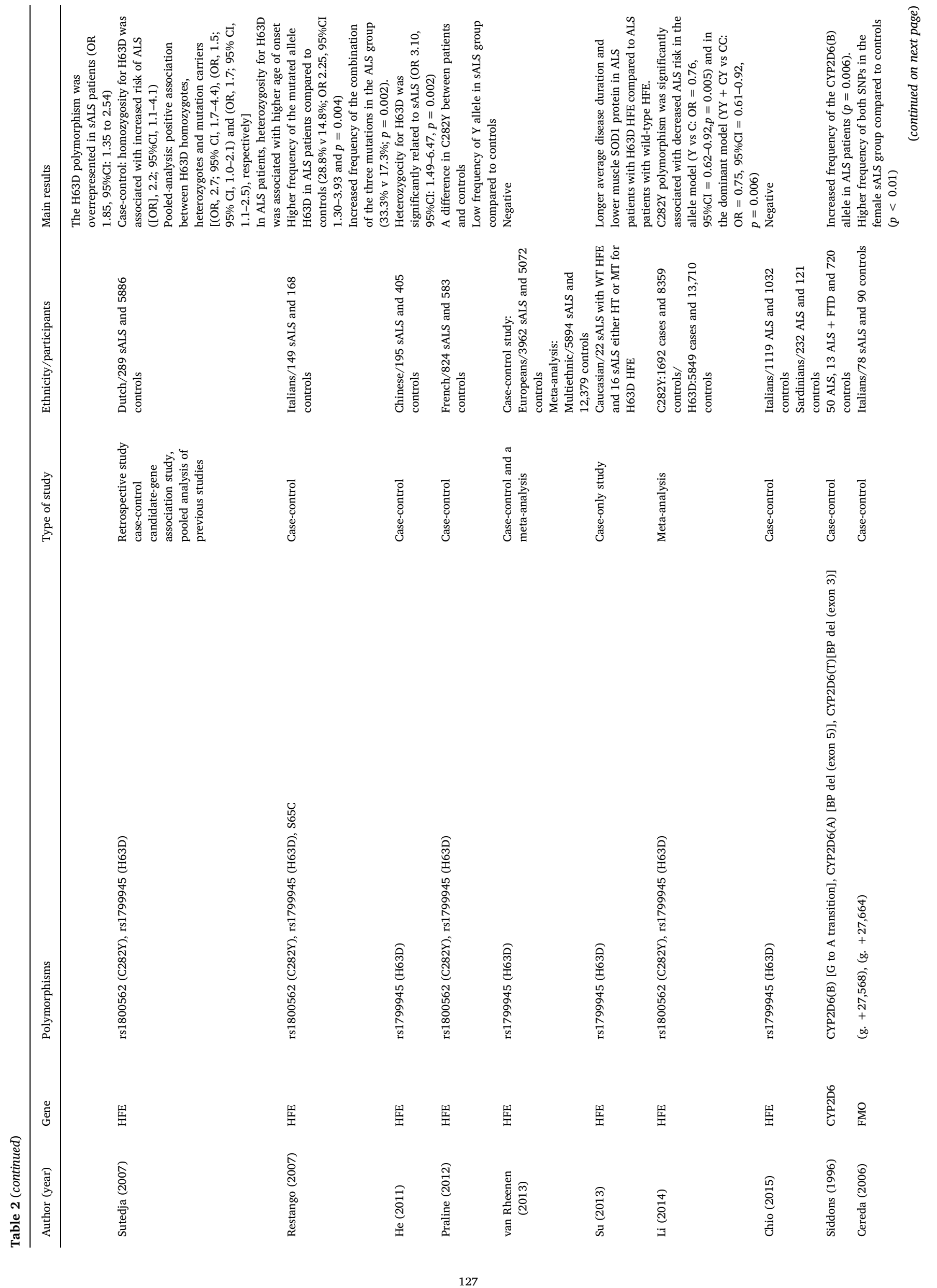




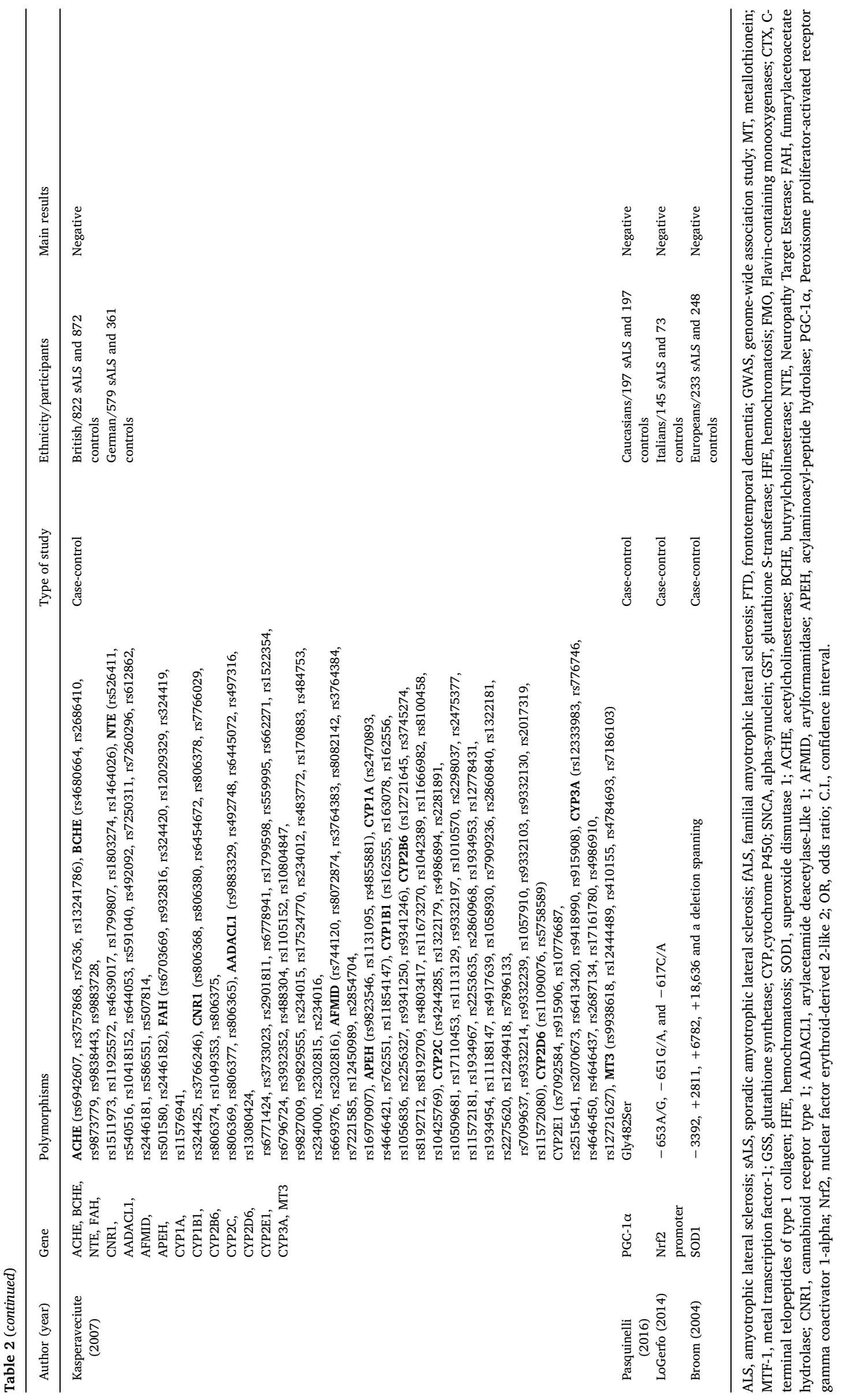




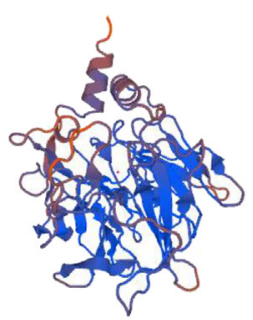

A

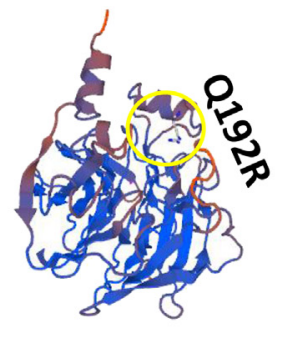

B

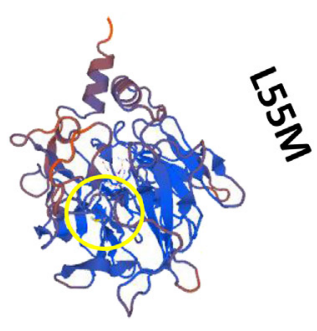

C
Fig. 1. A. The 3D model of the normal PON1 protein; B. The 3D model of the mutant Q192R PON1 protein; C. The 3D model of the mutant L55M PON1 protein; D. Parathion, diazinon and chlorpyrifos are oxidized by liver's cytochrome P450 to their corresponding oxons. Paraoxonase 1 (PON1) catalyzes the hydrolysis (detoxification) of these products, leading to the metabolites: diethylphosphate (DEP), para-nitrophenol (PNP), methylpyrimidinol (MHP) and trichloropyridinol (TCP). Variants across PON1 gene influence the concentration of paraoxonase- 1 enzyme in the serum, the protein stability and its catalytic activity, resulting in defective detoxification.

D

Parathion $\longrightarrow$ Paroxon

and 49 from rural areas) (Diekstra et al., 2009). Significant association for L55M, (rs854560) and also a weaker signal from Q192R (rs662) were observed. The R192/L55 haplotype was underrepresented in rural residents (Diekstra et al., 2009). Finally, in the rural group, increased load of $\mathrm{M}$ allele of L55M was associated with decreased survival (Diekstra et al., 2009).

In contrast to the limited number of studies with gene-environment interaction design, quite a few case-control studies have examined the role of PON1 variants in sALS. In a study of 166 Polish Caucasians patients with sALS, the genotype with R allele of rs662 was significantly associated with sALS (Slowik et al., 2006). Moreover, rs854560 PON1 was found to be associated with sALS in the Irish population (Cronin et al., 2007). Finally, in a cohort consisted of UK and US sALS patients, rs2074351 and rs705382 as well as 5-SNP haplotypes (rs854565/ rs2299261/rs705381/rs705382/rs4141217) were associated with sALS (Landers et al., 2008).

In contrast to the previous findings, there are also negative reports concerning the association between the previously referred PON1 polymorphism and sALS. SNPs across PON1 failed to show evidence about in North American, French, Canadian, Swedish, English, Italian, Chinese, Polish, Dutch, British, German cohorts (Chen et al., 2012a; Kasperaviciute et al., 2007; Ricci et al., 2011; Saeed et al., 2006; Valdmanis et al., 2008; van Blitterswijk et al., 2012; Zawislak et al., 2010). Furthermore, two meta-analyses have revealed negative results (Lee et al., 2015; Wills et al., 2009). (Lee et al., 2015). In view of the previous results, the role of PON1 gene in sALS remains uncertain. However, the strongest indication exists for rs854560 (L55M), rs662(Q192R), rs2074351 and rs705382.

Paraoxonase-2 and paraoxonase-3 genes: PON2 and PON3 enzymes metabolize oxidized lipids and protect against lipid peroxidation. They are not involved though in organophosphate metabolism, like PON1 enzyme (Ng et al., 2001; Reddy et al., 2001; Wills et al., 2009). The risk alleles of the non-synonymous coding PON2 polymorphisms rs6954345 and rs12026 have been associated with lower PON activity (Cronin et al., 2007). The possibility that individuals carrying the $C$ allele of the
PON2 C311S polymorphism may be more susceptible to ALS was tested in a case-control study of Polish population, revealing an association between the $\mathrm{C}$ allele and sALS in dominant and additive models (Slowik et al., 2006). However, the $S$ allele has also been found to confer susceptibility to neurodegeneration, as the SS genotype of the S311C PON2 polymorphism (SS genotype) has been associated with the risk of $\mathrm{AD}$ in a recent meta-analysis (Nie et al., 2017). Moreover, the intronic variants rs10487132 (PON3) and rs11981433 (PON2), were associated with sALS in the trio model (parents-affected child triad). Specifically, rs10487132 was associated with sALS in 450 nuclear pedigrees, comprising trios and discordant sibpairs (Saeed et al., 2006). Rs10487132 (PON3) has been reported to be associated with sALS in a cohort consisting of 166 Irish sALS patients and 437 controls (Cronin et al., 2007). However, PON2 and PON3 variants failed to reach any statistical significance in case-control models, in several cohorts (Chen et al., 2012a; Chen et al., 2012b; Kasperaviciute et al., 2007; Ricci et al., 2011; Saeed et al., 2006; van Blitterswijk et al., 2012). Rs978903 (PON3) and rs11981433 (PON2) have also been meta-analyzed by Willis et al. revealing negative association with ALS (Wills et al., 2009). The culture of null hypothesis significance testing may be considered as a factor for the lack of reproducibility of the positive results (Lash, 2017).

Haplotypes of SNPs of PON1, PON2 and PON3 have also been examined. Cronin et al. reported significant association between sALS and the haplotype of the risk alleles of rs854560 (PON1) and rs10487132 (PON3) in an Irish population. Significant association was also reported between sALS and the haplotype of the alleles of rs854560 (PON1), rs705381 (PON1) and rs10487132 (PON3) (Cronin et al., 2007). Additionally, the R-C haplotype, consisting of the R allele of rs662 (PON1) and the C of C3111S (PON2) was overrepresented among polish sALS patients (Slowik et al., 2006). It is possible that each SNP may confer partial susceptibility to ALS development, possibly, under gene to gene interaction with other polymorphisms across PON1, PON2 and PON3 genes. 


\subsection{ALAD and VDR}

The d-aminolevulinic acid dehydratase (ALAD) enzyme, which is also known as porphobilinogen synthase, is mainly expressed in liver and erythrocytes (Wetmur, 1994). The main function of this enzyme is to catalyze the second step in heme synthesis, by adding two molecules of aminolevulinic acid. In this way, a precursor of heme, cobalaminsmonopyrrole-porphobilinogen, is synthesized (Jaffe, 2000). The ALAD gene seems to influence the toxicokinetics of lead. The non-synonymous coding polymorphism, K59N (G177C), results from the substitution of G with $\mathrm{C}$ dinucleotide, at the coding position 177 . This leads to the conversion of lysine $(\mathrm{K})$ into asparagine $(\mathrm{N})$, creating the ALAD 2 variant allele, which is opposite to the ALAD 1 wild type allele (Wetmur, 1994). The ALAD-2 protein has been associated with lead levels, lower in the bones and higher in the blood (Kelada et al., 2001). Due to higher electronegativity, it enchains lead tighter than the less electronegative ALAD 1 protein (Bergdahl et al., 1997). This could alter the toxicokinetics of lead, especially among high-dose populations, leading to longer abidance of lead in blood and tissues (Kelada et al., 2001). The subsequent toxic effect results by two ways; either from the longer effect of lead; or from the abundant accumulation of aminolevulinic acid, due to ALAD inhibition (Kelada et al., 2001).

Fang et al. recruited 184 ALS cases and 194 controls of US veterans and performed a case-control study of gene-environment interaction. They mainly focused on K59N polymorphism and blood lead levels. In addition to blood lead measurements, the authors also measured plasma biomarkers of bone formation [procollagen type 1 aminoterminal peptide (PINP)] and resorption [C-terminal telopeptides of type 1 collagen (CTX)]. No association between ALAD (ALAD2 carriers VS ALAD1-1 homozygotes) and ALS was revealed, apart from ALAD1-1 carriers after adjustment for age and CTX (Fang et al., 2010). On the contrary, another case-control study of gene-environment interaction, with 109 ALS patients and 256 controls, showed a relationship between ALS and ALAD 2 allele. Blood and bone (patella and tibia) lead levels were measured. Specifically, the ALAD 2 allele was associated with decreased levels of lead in patella and tibia but appeared to be unrelated to blood lead levels (Kamel et al., 2005; Kamel et al., 2003). Moreover, the authors identified IVS2 + 299G > A, a previously unreported polymorphism at the Msp1 site in intron 2. This polymorphism was associated with a significant decrease in bone lead levels and ALS risk (Kamel et al., 2003).

Vitamin D may affect absorption and distribution of lead (Fullmer, 1992). The vitamin D receptor (VDR) gene encodes the vitamin D receptor protein. The BB genotype of the intronic Bsml polymorphism between exons 8 and 9 may influence calcium absorption and distribution (Zmuda et al., 2000). Consequently, the BB genotype may affect lead toxicity (Kamel et al., 2003). However, it is rather unlikely that an intronic polymorphism, such as Bsml, represents a functional loci across VDR gene (Zmuda et al., 2000). Therefore, the coexistence of a proximal exonic SNP, high lead dose and Bsml polymorphism, may lead to defective VDR function (Fang et al., 2010). However, Kamel et al. reported negative results concerning Bsml and its effect on lead levels and/or ALS development (Kamel et al., 2003).

The Fokl functional VDR polymorphism has been associated with PD and with the cognitive decline in PD (Gatto et al., 2016; Lee et al., 2014; Niu et al., 2015). ApaI, BsmI, and TaqI polymorphisms have not been associated with susceptibility to PD (Lee et al., 2014; Niu et al., 2015). Furthermore, associations between VDR polymorphisms (TaqI and ApaI) and $\mathrm{AD}$ susceptibility have been reported (Laczmanski et al., 2015; Lee et al., 2014), depending though on ethnicity and climatic conditions (Laczmanski et al., 2015). The possible existence of geneenvironment interactions may explain, to some degree, the lack of association (Kang et al., 2016). Therefore, despite the lack of association between VDR SNPs and ALS, there is some indication for their contribution to neurodegeneration.

\subsection{SNCA}

SNCA constitutes a major component of pathological features in PD and MSA, such as Lewy bodies, neurites and glial cytoplasmic inclusions (Mollenhauer et al., 2011; Wakabayashi et al., 1998). It is also considered to be a risk factor for these diseases (Al-Chalabi et al., 2009; Xiromerisiou et al., 2010). There is evidence of overlapping clinical phenotypes among PD, ALS, and MSA, suggesting that SNCA may confer susceptibility to ALS (Guo et al., 2014). Moreover, pesticides expedite the rate of a-syn fibrillation. PD animal models with a transgenic a-syn, revealed increased a-syn pathology, when exposed to pesticides (Gao and Hong, 2011; Uversky et al., 2001). Therefore, SNCA may influence the risk of ALS by affecting neuronal toxicity, under combined interaction with pesticides. In total, 5 SNPs across SNCA have been examined, up to now (rs2736990, rs356220, s3775444, rs3822086 and rs11931074) (Guo et al., 2014) producing negative results (Chen et al., 2015; Guo et al., 2014).

Previous studies examining the interaction between REP1 SNCA polymorphism and pesticide exposure in PD etiology, yielded little evidence of an involvement as risk factors or as effect modifiers. These studies though limited by small sample size or assessment of pesticide exposure (Brighina et al., 2008; Gatto et al., 2010). Also, GG genotype of rs10516846 across SNCA gene, may be associated with an increased risk of $\mathrm{AD}$ and elevated SNCA level in CSF (Wang et al., 2016). Therefore, the overall contribution of SNCA SNPs to neurodegeneration seems unlikely.

\subsection{MT family genes, MTF-1, GSS}

Metallothioneins (MTs) are a family of metal $(\mathrm{Cu} / \mathrm{Zn})$-binding proteins. Metallothionein-I (MT-I) and metallothionein-II (MT-II) are present in all human tissues, while Metallothionein-III (MT-III) mainly exists in the central nervous system and metallothionein-IV in the stratified squamous epithelia (Thirumoorthy et al., 2011). The Metallothionein (MT) family is implicated in heavy metal detoxification pathways. Lack of MT-I and MT-II is associated with increased heavy metal toxicity (Liu et al., 1995), while overexpression of MT seems to have a protective role (Klaassen and Liu, 1998). Deficiencies in MT isoforms may also influence the cellular defensive mechanisms against heavy metals, as MTs increase the cellular export and reduce the cellular uptake of heavy metals. They accomplish these procedures through sequestration of free toxic metal in the cell (Morahan et al., 2007a). Metal transcription factor-1 (MTF-1) influences MT gene expression related to heavy metals and, consequently, the damage of motor neurons (Gunther et al., 2012; Morahan et al., 2007c). Glutathione is possibly involved in the detoxification mechanisms regarding pesticides and heavy metals (Abel et al., 2004; Jozefczak et al., 2012).

One case-control study with gene-environment interaction examined the possibility that individuals carrying specific MT, MTF-1 and GSS polymorphisms, may be more vulnerable to ALS development. The sample consisted of 186 sALS and 186 controls with European ancestry (Morahan et al., 2007c). MT-I Isoforms: C allele and C/C genotype of M1 isoform were reported to be more frequent in all sALS patients and even more frequent in the male sALS subgroup. Additionally, M1C/C genotype was found to increase the risk of sALS, while M5 A/A genotype revealed a protective effect. The most common haplotype, CGGGGGGG, which was constructed by the examined MT-I SNPs, was more frequent in the sALS group (26\%) compared to controls $(18 \%)(p=0.032)$. Also, the GGAGAGGG haplotype was more frequent in controls $(12 \%)$ than in the sALS group (7\%). When the M1 SNP was included in the analysis, the haplotype difference between the groups was found to be stronger ( $p=0.019$ vs $p=0.026$ ). Also, the GAG haplotype of M2-M4 SNPs had a decreased frequency in the sALS group. The subsequent analysis for gene-environment interactions yielded negative results (Morahan et al., 2007c). MT-IIa gene: no significant association was revealed. MTF-1 
gene: F2 MTF-1 C allele, $\mathrm{C} / \mathrm{C}$ and $\mathrm{C} / \mathrm{T}$ genotypes were more common in female sALS patients but not in the total patients or in the male sALS group, compared to controls. Only rare haplotypes (frequency $<2 \%$ ) differed significantly between patients and controls. Therefore, the authors suggested that it is rather unlikely to expose biological effects. GSS gene: GSS genotype-metal interactions differed between sALS patients and healthy individuals. Moreover, an association was reported between the GCGC haplotype and sALS, when patients exposed to metal were compared to those exposed to solvents/chemicals. Neither an association trend nor interactions were observed for herbicide/pesticide exposure (Morahan et al., 2007c).

Morahan et al., after the identification of eight novel SNPs in the 5' untranslated region and in the intron 2 of MT3, performed a casecontrol study. Despite the significant difference in the genotype distribution of the SNP (A1422C) between sALS and controls, the authors suggested that this association might not be biologically relevant. They concluded that the variants of MT3 gene are unlikely to be responsible for susceptibility to sALS (Morahan et al., 2005; Morahan et al., 2007c). They were also interested in examining differences in methylation levels of the CpG islands of MT-Ia and MT-IIa isoforms, between sALS patients and controls. However no significant divergence was observed (Morahan et al., 2007a).

Hayasi et al. screened 37 Japanese sALS and 206 sex-matched healthy controls for mutations across MT-IIA promoter and MT-III genes. Only the novel A/G SNP ( -5 ) on MT-IIA promoter was detected. However, it is rather unlikely for this SNP to influence the clinical type, the progression rate or the age of onset (Hayashi et al., 2006). Kasperaveciute et al. have also reported negative results, regarding the role of MT-III gene polymorphisms in sALS (Kasperaviciute et al., 2007).

\subsection{FMO}

Flavin-containing monooxygenase (FMO) proteins belong to the family of microsomal enzymes catalyzing the oxidation of several endogenous and exogenous factors, including drugs (Cashman, 2000). Additionally, yeast FMO (yFMO) is involved in redox balance, by catalyzing the oxidation of biological thiols, such as the oxidation of reduced glutathione (GSH) to glutathione disulfide (GSSG) (Cereda et al., 2006; Suh et al., 2000). Mutated alleles of two SNPs on the 3-UTR of FMO gene $(\mathrm{g} .+27,568)$ and $(\mathrm{g} .+27,664)$ have been found to influence together the sALS risk. However, interdependent action of them and the gender specific effect cannot be excluded (Cereda et al., 2006).

\subsection{SOD1, HFE, Transferrin, GSTs, PGC-1 $\alpha$ and Nrf2}

Oxidative stress contributes to the neurodegenerative process of neurological disorders, including ALS (Cookson and Shaw, 1999; Dardiotis et al., 2013a). Cu,Zn superoxide dismutase (SOD1) is the first identified genetic risk factor for approximately $20 \%$ of familial and $3 \%$ of sporadic ALS cases (Hayashi et al., 2016). Several pathophysiological mechanisms, regarding the implication of SOD1 to ALS, have been proposed, including oxidative stress, mitochondrial dysfunction and excitotoxicity (Hayashi et al., 2016). Broom et al. recruited 233 sALS cases and 248 healthy controls and genotyped them for four SNPs $(-3392,+2811,+6782,+18,636)$ and for deletion spanning across SOD1 gene (Broom et al., 2004). However, they did not confirm any connection between polymorphisms or their haplotypes and sALS susceptibility, age of onset, survival, and site of onset (Broom et al., 2004).

The $\mathrm{G}$ allele of the rs2070424 SOD1 polymorphism appeared to have a protective role against AD in a Polish study (Spisak et al., 2014).

Oxidative stress is also influenced by iron accumulation. Defective iron homeostasis is associated with oxidative damage (Wang et al., 2004). Iron related genes may either cause or predispose to dopaminergic cell damage, possibly due to the contribution of iron to the synthesis of tyrosine hydroxylase (Snyder and Connor, 2009). Mutations in the Hfe gene are associated with hemochromatosis, a disease that is characterized by iron overload (Hanson et al., 2001). Therefore, the Hfe variants could be implicated to ALS pathophysiology, through metal-mediated oxidative stress (Wang et al., 2004). H63D polymorphism across HFE gene was found to accelerate the progression of ALS in SOD1 transgenic mice (Nandar et al., 2014). Moreover, SOD1 ALS patients, carrying the risk G allele of H63D, had a significantly longer survival compared to those with the wild type genotype (Chio et al., 2015). Additionally, sALS patients, homozygotes or heterozygotes for H63D mutant allele, were reported to have 28.1 months longer average disease duration and 39.3\% lower muscle SOD1 protein compared to homozygotes for the wild type allele (Su et al., 2013). Transferrin is a transmembrane iron-transport glycoprotein that binds to iron tightly and reversibly. The rs1049296 polymorphism across transferrin has been associated with increased PD and AD risk (Rhodes et al., 2014; Wang et al., 2013). Transferrin also interacts with HFE (Namekata et al., 1997). GSTO1 and 2 are members of the GST family and they are abundant in the whole human body, but less in the brain (Wang et al., 2005). They influence the reduction of oxidative stress, through glutathione-dependent detoxification (Van De Giessen et al., 2008). Rs4925 (Ala140Asp) is a functional SNP decreasing thioltransferase activity of the wild-type GSTO1 (Tanaka-Kagawa et al., 2003). Several SNPs have been associated with age of fALS onset. However, this association was evident only in a Swedish cohort. Possibly, the reported marginal trends could imply that variations across GST genes may be phenotypically evident in certain ethnic groups (Van De Giessen et al., 2008).

Quite a few case-control studies have been conducted examining the role of HFE polymorphisms in sALS. Higher frequency of the mutated allele was revealed in ALS patients than in controls. Moreover, H63D or $\mathrm{C} 282 \mathrm{Y}$ mutations were associated with a decrease in h-actin, a-tubulin and $\mathrm{Cu} / \mathrm{Zn}$-SOD1 expression compared to wild types, thus indicating alterations in axonal transport (Wang et al., 2004). H63D polymorphism was overrepresented in sporadic ALS individuals (Goodall et al., 2005). Increased risk of ALS was also revealed in an Italian population with sALS, resulting from H63D risk allele, as well as from the combination of C282Y, H63D and S65C risk alleles (Restagno et al., 2007). Dutch homozygotes for H63D revealed an increased risk for developing ALS (Sutedja et al., 2007). Heterozygocity for H63D was significantly related to sALS in a Chinese cohort (He et al., 2011). Additionally, a lower frequency of the Y allele of C282Y was reported in a French sALS group compared to controls (Praline et al., 2012). Carriers of the H63D variant allele had increased risk for ALS compared to noncarriers, but the ALS risk seems to be independent of C282Y, TfC2 and GSTP1 mutations. Moreover, H63D was noted to affect patella and tibia lead levels, associated with ALS. Specifically, in sALS patients, C282Y was associated with patella and tibia lead levels, while GSTP1 was related to blood lead levels (Eum et al., 2015). Additionally, there is strong evidence that $\mathrm{H} 63 \mathrm{D}$ polymorphism has a protective role against AD risk (Lin et al., 2012), while there is only mild indication that the C282Y polymorphism protects against PD (Duan et al., 2016; Xia et al., 2015).

Negative results have also been reported for both C282Y and H63D (van Rheenen et al., 2013; Yen et al., 2004). Additionally, two metaanalyses have been performed so far, concerning FHE SNPs and ALS. The first one revealed negative correlation (van Rheenen et al., 2013). On the contrary, the second and most recent one yielded a significant OR for C282Y polymorphism. More precisely, C282Y was significantly associated with decreased ALS risk, in a specific allele model (Y vs C: $\mathrm{OR}=0.76,95 \% \mathrm{CI}=0.62-0.92, p=0.005)$ and also in the dominant model of this allele (YY + CY vs CC: OR $=0.75,95 \% \mathrm{CI}=0.61-0.92$, $p=0.006$ ) (Li et al., 2014). Results from pooled-analysis suggested a positive association between ALS and H63D homozygotes, heterozygotes and mutation carriers. Moreover, an association between heterozygosity for H63D and a higher age of onset was observed in ALS patients (Sutedja et al., 2007).

Peroxisome proliferator-activated receptor $\gamma$ coactivator $1 \alpha$ (PGC- 
$1 \alpha$ ), consists a transcriptional co-activator, which mainly regulates mitochondrial biogenesis and contributes to antioxidant defense mechanisms (Qi et al., 2015). Gly482Ser SNP has been associated with a decreased gene expression and a reduction in the activity of PCG-1 $\alpha$ (Prior et al., 2012). ALS carriers of the Gly482Ser polymorphism show increased exercise-related oxidative stress, despite the lack of strong evidence of association between Gly482Ser and ALS (Pasquinelli et al., 2016). The intracellular redox balance is also influenced from the nuclear factor erythroid-derived 2-like 2 (NFE2L2/Nrf2) pathways. However, $-653 \mathrm{~A} / \mathrm{G},-651 \mathrm{G} / \mathrm{A}$, and $-617 \mathrm{C} / \mathrm{A}$ SNPs across the Nrf2 gene promoter, which had previously been reported to have functional significance and/or influence on basal Nrf2 expression and function, did not reveal any association with increased ALS risk (LoGerfo et al., 2014; Marzec et al., 2007).

\subsection{Other genes}

Several variants across CYP2D6 gene were reported to influence the expression and activity of CYP2D enzyme and, consequently, the metabolism of xenobiotics. Organophosphate compounds, triazine (atrazine), carbamates (carbaryl, maneb, ziram) and 1-methyl-4-phenyl1,2,3,6-tetrahydropyridine (MPTP) are metabolized to some degree by the cytochrome (CYP) P450 enzyme CYP2D6 (Neafsey et al., 2009; Zhou, 2009). Rs389209 [CYP2D6*4 (G > A)] polymorphism may represent a variant with a significant functional effect. More specifically, homozygotes for A allele revealed defective CYP2D6 activity, compared to those with AG and GG genotypes. Moreover, this SNP is responsible for aberrant mRNA splicing at intron3/exon4 boundary, causing an early termination (Dardiotis et al., 2013b; Gough et al., 1990).

Sibbons et al. examined the following polymorphisms: CYP2D6(B) [G to A transition], CYP2D6(A) [BP del (exon 5)], CYP2D6(T)[BP del (exon 3)]. They detected an increased frequency of CYP2D6 (B) allele in ALS patients (Siddons et al., 1996). Kasperveciute et al., examined quite a few polymorphisms across CYP1A, CYP1B1, CYP2B6, CYP2C, CYP2D6, CYP2E1 and CYP3A for possible connection with sALS. The results of this study, however, failed to reach any statistical significant threshold among British and German cohorts (Kasperaviciute et al., 2007). In the same study, authors also analyzed a few additional genes that are involved in xenobiotic metabolism pathways [PON1, PON2 and MT3, which are described in the corresponding sections, as well as acetylcholinesterase (ACHE), butyrylcholinesterase (BCHE), Neuropathy Target Esterase (NTE), fumarylacetoacetate hydrolase (FAH), cannabinoid receptor type 1 (CNR1), arylacetamide deacetylase-Llke 1 (AADACL1), arylformamidase (AFMID) and acylaminoacyl-peptide hydrolase (APEH)], showing negative results (Kasperaviciute et al., 2007).

\section{Concluding remarks}

Both genetic and environmental factors are supposed to increase susceptibility to ALS development. Unfortunately, there are a relatively small number of studies examining the interactions between genetic and environmental factors. It is also evident that each determinant may have a minor effect on ALS risk. In view of the former evidence, studies estimating the combined effect and the interactions between genetic and environmental factors are more likely to detect relevant associations, than analyze them separately.

Human genetic association studies examining the interaction between genes and pesticides or metal exposure, on the risk of ALS, have provided remarkable results. More precisely, based on our results, PON1 [rs854560(L55M), rs662(Q192R), rs2074351 and rs705382], PON2 (C311S, rs11981433) and PON3 (rs10487132) seem to be the most significant genes that are implicated in pesticides metabolism and possibly influence ALS development. As far as the genetic variants that are implicated in lead toxicity are concerned, the strongest indications derived from ALAD [rs1800435 (K59N), IVS2 + 299G > A] and VDR
(Bsml) variants. Finally, a few evidence exist for MT-III (A1422C), MT-I (upstream rs7403881) and GSS, which are implicated in heavy metal detoxification pathways, as well as for HFE [rs1800562 (C282Y), rs1799945 (H63D)] genes that possibly affect oxidative stress and, consequently, iron accumulation. Of note, genetic association studies examining the interaction between genes and pesticides or metal exposure, have also revealed associations with other neurological diseases (AD, PD, MS and IS). The majority of them concerned AD and PD, suggesting an overall effect and interaction between polymorphisms implicated in detoxification pathways and neurodegeneration.

Among the environmental toxicants, pesticides appear to be the strongest risk factors for to ALS. Milder indications, though, exist for heavy metals, mercury, selenium, mercury, cadmium, iron, lead and xenobiotics. Therefore, both toxicants themselves, and genetic variability that influences these metabolic pathways, appear to interact to increase susceptibility for ALS. However, studies examining the role of both toxicants and genetic variability as ALS risk factors, and their interactions, are relatively few. In view of the former considerations, definitive conclusions whether toxicants are the primary cause and the genes are additional factors for ALS development, or vice versa, cannot be drawn so far.

It has been indicated that genetic susceptibility, either in pesticide metabolism or in heavy metal detoxification pathways and toxicokinetics of lead, may increase the risk of ALS development. However, this indication is limited and uncertain at the present. The culture of null hypothesis significance testing may be considered as a factor for the lack of reproducibility of the positive results (Lash, 2017). By correct use and interpretation of statistical value, the misinterpretation of $p$-values, confidence intervals and statistical tests in general, could be avoided (Greenland, 2017). The scientific reasoning could not be substitute from single statistical value, index or test (Rothman, 2016; Wasserstein and Lazar, 2016). Therefore, it is of great necessity more studies with gene-environment interaction design, and studies investigating the etiologic role of assuming both environmental and genetic factors have to be conducted in the future, in order for the pathogenic mechanisms of ALS to be elucidated.

\section{Acknowledgements}

'Declarations of interest: none'

This research did not receive any specific grant from funding agencies in the public, commercial, or not-for-profit sectors.

\section{References}

Abel, E.L., Bammler, T.K., Eaton, D.L., 2004. Biotransformation of methyl parathion by glutathione S-transferases. Toxicol. Sci. 79, 224-232.

Adkins, S., Gan, K.N., Mody, M., La Du, B.N., 1993. Molecular basis for the polymorphic forms of human serum paraoxonase/arylesterase: glutamine or arginine at position 191, for the respective A or B allozymes. Am. J. Hum. Genet. 52, 598-608.

Al-Chalabi, A., Hardiman, O., 2013. The epidemiology of ALS: a conspiracy of genes, environment and time. Nat. Rev. Neurol. 9, 617-628.

Al-Chalabi, A., Durr, A., Wood, N.W., Parkinson, M.H., Camuzat, A., Hulot, J.S., Morrison, K.E., Renton, A., Sussmuth, S.D., Landwehrmeyer, B.G., Ludolph, A., Agid, Y., Brice, A., Leigh, P.N., Bensimon, G., 2009. Genetic variants of the alpha-synuclein gene SNCA are associated with multiple system atrophy. PLoS One 4, e7114.

Androutsopoulos, V.P., Kanavouras, K., Tsatsakis, A.M., 2011. Role of paraoxonase 1 (PON1) in organophosphate metabolism: implications in neurodegenerative diseases. Toxicol. Appl. Pharmacol. 256, 418-424.

Appel, S.H., Zhao, W., Beers, D.R., Henkel, J.S., 2011. The microglial-motoneuron dialogue in ALS. Acta Myol.: Myopathies and Cardiomyopathies 30, 4-8.

Baltazar, M.T., Dinis-Oliveira, R.J., de Lourdes Bastos, M., Tsatsakis, A.M., Duarte, J.A., Carvalho, F., 2014. Pesticides exposure as etiological factors of Parkinson's disease and other neurodegenerative diseases-a mechanistic approach. Toxicol. Lett. 230, 85-103.

Bergdahl, I.A., Grubb, A., Schutz, A., Desnick, R.J., Wetmur, J.G., Sassa, S., Skerfving, S., 1997. Lead binding to delta-aminolevulinic acid dehydratase (ALAD) in human erythrocytes. Pharmacol. Toxicol. 81, 153-158.

Bozzoni, V., Pansarasa, O., Diamanti, L., Nosari, G., Cereda, C., Ceroni, M., 2016. Amyotrophic lateral sclerosis and environmental factors. Funct. Neurol. 31, 7-19.

Brighina, L., Frigerio, R., Schneider, N.K., Lesnick, T.G., de Andrade, M., Cunningham, J.M., Farrer, M.J., Lincoln, S.J., Checkoway, H., Rocca, W.A., Maraganore, D.M., 
2008. Alpha-synuclein, pesticides, and Parkinson disease: a case-control study. Neurology 70, 1461-1469.

Broom, W.J., Parton, M.J., Vance, C.A., Russ, C., Andersen, P.M., Hansen, V., Leigh, P.N., Powell, J.F., Al-Chalabi, A., Shaw, C.E., 2004. No association of the SOD1 locus and disease susceptibility or phenotype in sporadic ALS. Neurology 63, 2419-2422.

Brophy, V.H., Jampsa, R.L., Clendenning, J.B., McKinstry, L.A., Jarvik, G.P., Furlong, C.E., 2001. Effects of 5' regulatory-region polymorphisms on paraoxonase-gene (PON1) expression. Am. J. Hum. Genet. 68, 1428-1436.

Capozzella, A., Sacco, C., Chighine, A., Loreti, B., Scala, B., Casale, T., Sinibaldi, F., Tomei, G., Giubilati, R., Tomei, F., Rosati, M.V., 2014. Work related etiology of amyotrophic lateral sclerosis (ALS): a meta-analysis. Ann. Ig. 26, 456-472.

Cashman, J.R., 2000. Human flavin-containing monooxygenase: substrate specificity and role in drug metabolism. Curr. Drug Metab. 1, 181-191.

Cereda, C., Gabanti, E., Corato, M., De silvestri, A., Alimonti, D., Cova, E., Malaspina, A., Ceroni, M., 2006. Increased incidence of FMO1 gene single nucleotide polymorphisms in sporadic amyotrophic lateral sclerosis. Amyotroph. Lateral Scler. 7, 233-240.

Chen, Y., Huang, R., Chen, K., Song, W., Yang, Y., Zhao, B., Li, J., Shang, H.F., 2012a. Association analysis of PON polymorphisms in sporadic ALS in a Chinese population. Neurobiol. Aging 33 (2949), e2941-2943.

Chen, Y., Zeng, Y., Huang, R., Yang, Y., Chen, K., Song, W., Zhao, B., Li, J., Yuan, L. Shang, H.F., 2012b. No association of five candidate genetic variants with amyotrophic lateral sclerosis in a Chinese population. Neurobiol. Aging 33 (2721), e2723-2725.

Chen, S., Sayana, P., Zhang, X., Le, W., 2013. Genetics of amyotrophic lateral sclerosis: an update. Mol. Neurodegener. 8, 28.

Chen, Y., Wei, Q.Q., Ou, R., Cao, B., Chen, X., Zhao, B., Guo, X., Yang, Y., Chen, K., Wu, Y., Song, W., Shang, H.F., 2015. Genetic variants of SNCA are associated with susceptibility to Parkinson's disease but not amyotrophic lateral sclerosis or multiple system atrophy in a Chinese population. PLoS One 10, e0133776.

Chio, A., Mora, G., Sabatelli, M., Caponnetto, C., Lunetta, C., Traynor, B.J., Johnson, J.O., Nalls, M.A., Calvo, A., Moglia, C., Borghero, G., Monsurro, M.R., La Bella, V., Volanti, P., Simone, I., Salvi, F., Logullo, F.O., Nilo, R., Giannini, F., Mandrioli, J., Tanel, R., Murru, M.R., Mandich, P., Zollino, M., Conforti, F.L., Penco, S., Brunetti, M., Barberis, M., Restagno, G., 2015. HFE p.H63D polymorphism does not influence ALS phenotype and survival. Neurobiol. Aging 36 (2906), e2907-2911.

Cookson, M.R., Shaw, P.J., 1999. Oxidative stress and motor neurone disease. Brain Pathol. (Zurich, Switzerland) 9, 165-186.

Costa, L.G., Giordano, G., Cole, T.B., Marsillach, J., Furlong, C.E., 2013. Paraoxonase 1 (PON1) as a genetic determinant of susceptibility to organophosphate toxicity. Toxicology 307, 115-122.

Cronin, S., Greenway, M.J., Prehn, J.H., Hardiman, O., 2007. Paraoxonase promoter and intronic variants modify risk of sporadic amyotrophic lateral sclerosis. J. Neurol. Neurosurg. Psychiatry 78, 984-986.

Dardiotis, E., Panayiotou, E., Feldman, M.L., Hadjisavvas, A., Malas, S., Vonta, I., Hadjigeorgiou, G., Kyriakou, K., Kyriakides, T., 2013a. Intraperitoneal melatonin is not neuroprotective in the G93ASOD1 transgenic mouse model of familial ALS and may exacerbate neurodegeneration. Neurosci. Lett. 548, 170-175.

Dardiotis, E., Xiromerisiou, G., Hadjichristodoulou, C., Tsatsakis, A.M., Wilks, M.F., Hadjigeorgiou, G.M., 2013b. The interplay between environmental and genetic fac tors in Parkinson's disease susceptibility: the evidence for pesticides. Toxicology 307, $17-23$

Deziel, N.C., Friesen, M.C., Hoppin, J.A., Hines, C.J., Thomas, K., Freeman, L.E., 2015. A review of nonoccupational pathways for pesticide exposure in women living in agricultural areas. Environ. Health Perspect. 123, 515-524.

Diekstra, F.P., Beleza-Meireles, A., Leigh, N.P., Shaw, C.E., Al-Chalabi, A., 2009. Interaction between PON1 and population density in amyotrophic lateral sclerosis. Neuroreport 20, 186-190.

Duan, C., Wang, M., Zhang, Y., Wei, X., Huang, Y., Zhang, H., Cheng, L., Gai, Z., 2016. C282Y and H63D polymorphisms in hemochromatosis gene and Risk of Parkinson's disease: a meta-analysis. Am. J. Alzheimers Dis. Other Demen. 31, 201-207.

Eum, K.D., Seals, R.M., Taylor, K.M., Grespin, M., Umbach, D.M., Hu, H., Sandler, D.P., Kamel, F., Weisskopf, M.G., 2015. Modification of the association between lead exposure and amyotrophic lateral sclerosis by iron and oxidative stress related gene polymorphisms. Amyotroph. Lateral Scler. Frontotemp, Degener. 16, 72-79.

Fang, F., Kwee, L.C., Allen, K.D., Umbach, D.M., Ye, W., Watson, M., Keller, J., Oddone, E.Z., Sandler, D.P., Schmidt, S., Kamel, F., 2010. Association between blood lead and the risk of amyotrophic lateral sclerosis. Am. J. Epidemiol. 171, 1126-1133.

Fullmer, C.S., 1992. Intestinal interactions of lead and calcium. Neurotoxicology 13, 799-807.

Gao, H.M., Hong, J.S., 2011. Gene-environment interactions: key to unraveling the mystery of Parkinson's disease. Prog. Neurobiol. 94, 1-19.

Gatto, N.M., Rhodes, S.L., Manthripragada, A.D., Bronstein, J., Cockburn, M., Farrer, M., Ritz, B., 2010. Alpha-Synuclein gene may interact with environmental factors in increasing risk of Parkinson's disease. Neuroepidemiology 35, 191-195.

Gatto, N.M., Paul, K.C., Sinsheimer, J.S., Bronstein, J.M., Bordelon, Y., Rausch, R., Ritz, B., 2016. Vitamin D receptor gene polymorphisms and cognitive decline in Parkinson's disease. J. Neurol. Sci. 370, 100-106.

Gibb, H., O'Leary, K.G., 2014. Mercury exposure and health impacts among individuals in the artisanal and small-scale gold mining community: a comprehensive review. Environ. Health Perspect. 122, 667-672.

Goodall, E.F., Greenway, M.J., van Marion, I., Carroll, C.B., Hardiman, O., Morrison, K.E., 2005. Association of the H63D polymorphism in the hemochromatosis gene with sporadic ALS. Neurology 65, 934-937.

Gough, A.C., Miles, J.S., Spurr, N.K., Moss, J.E., Gaedigk, A., Eichelbaum, M., Wolf, C.R., 1990. Identification of the primary gene defect at the cytochrome P450 CYP2D locus. Nature 347, 773-776.
Greenland, S., 2017. Invited commentary: the need for cognitive science in methodology. Am. J. Epidemiol. 186, 639-645.

Gunther, V., Lindert, U., Schaffner, W., 2012. The taste of heavy metals: gene regulation by MTF-1. Biochim. Biophys. Acta 1823, 1416-1425.

Guo, X.Y., Chen, Y.P., Song, W., Zhao, B., Cao, B., Wei, Q.Q., Ou, R.W., Yang, Y., Yuan, L.X., Shang, H.F., 2014. SNCA variants rs2736990 and rs356220 as risk factors for Parkinson's disease but not for amyotrophic lateral sclerosis and multiple system atrophy in a Chinese population. Neurobiol. Aging 35 (2882), e2881-2886.

Hanson, E.H., Imperatore, G., Burke, W., 2001. HFE gene and hereditary hemochromatosis: a HuGE review. Human genome epidemiology. Am. J. Epidemiol. 154, 193-206.

Hardiman, O., Al-Chalabi, A., Chio, A., Corr, E.M., Logroscino, G., Robberecht, W., Shaw, P.J., Simmons, Z., van den Berg, L.H., 2017. Amyotrophic lateral sclerosis. Nat. Rev. Dis. Primers 3, 17085.

Hayashi, Y., Hashizume, T., Wakida, K., Satoh, M., Uchida, Y., Watabe, K., Matsuyama, Z., Kimura, A., Inuzuka, T., Hozumi, I., 2006. Association between metallothionein genes polymorphisms and sporadic amyotrophic lateral sclerosis in a Japanese population. Amyotroph. Lateral Scler. 7, 22-26.

Hayashi, Y., Homma, K., Ichijo, H., 2016. SOD1 in neurotoxicity and its controversial roles in SOD1 mutation-negative ALS. Adv. Biol. Regul. 60, 95-104.

He, X., Lu, X., Hu, J., Xi, J., Zhou, D., Shang, H., Liu, L., Zhou, H., Yan, B., Yu, L., Hu, F., Liu, Z., He, L., Yao, X., Xu, Y., 2011. H63D polymorphism in the hemochromatosis gene is associated with sporadic amyotrophic lateral sclerosis in China. Eur. J. Neurol. 18, 359-361.

Ingre, C., Roos, P.M., Piehl, F., Kamel, F., Fang, F., 2015. Risk factors for amyotrophic lateral sclerosis. Clin. Epidemiol. 7, 181-193.

Jaffe, E.K., 2000. The porphobilinogen synthase family of metalloenzymes. Acta Crystallogr. D Biol. Crystallogr. 56, 115-128.

Jozefczak, M., Remans, T., Vangronsveld, J., Cuypers, A., 2012. Glutathione is a key player in metal-induced oxidative stress defenses. Int. J. Mol. Sci. 13, 3145-3175.

Kamel, F., Umbach, D.M., Lehman, T.A., Park, L.P., Munsat, T.L., Shefner, J.M., Sandler, D.P., Hu, H., Taylor, J.A., 2003. Amyotrophic lateral sclerosis, lead, and genetic susceptibility: polymorphisms in the delta-aminolevulinic acid dehydratase and vitamin D receptor genes. Environ. Health Perspect. 111, 1335-1339.

Kamel, F., Umbach, D.M., Hu, H., Munsat, T.L., Shefner, J.M., Taylor, J.A., Sandler, D.P., 2005. Lead exposure as a risk factor for amyotrophic lateral sclerosis. Neurodegener. Dis. 2, 195-201.

Kamel, F., Umbach, D.M., Bedlack, R.S., Richards, M., Watson, M., Alavanja, M.C.R., Blair, A., Hoppin, J.A., Schmidt, S., Sandler, D.P., 2012. Pesticide exposure and amyotrophic lateral sclerosis. Neurotoxicology 33, 457-462.

Kanavouras, K., Tzatzarakis, M.N., Mastorodemos, V., Plaitakis, A., Tsatsakis, A.M., 2011. A case report of motor neuron disease in a patient showing significant level of DDTs, HCHs and organophosphate metabolites in hair as well as levels of hexane and toluene in blood. Toxicol. Appl. Pharmacol. 256, 399-404.

Kang, S.Y., Park, S., Oh, E., Park, J., Youn, J., Kim, J.S., Kim, J.U., Jang, W., 2016. Vitamin D receptor polymorphisms and Parkinson's disease in a Korean population: revisited. Neurosci. Lett. 628, 230-235.

Kasperaviciute, D., Weale, M.E., Shianna, K.V., Banks, G.T., Simpson, C.L., Hansen, V.K., Turner, M.R., Shaw, C.E., Al-Chalabi, A., Pall, H.S., Goodall, E.F., Morrison, K.E., Orrell, R.W., Beck, M., Jablonka, S., Sendtner, M., Brockington, A., Ince, P.G., Hartley, J., Nixon, H., Shaw, P.J., Schiavo, G., Wood, N.W., Goldstein, D.B., Fisher, E.M., 2007. Large-scale pathways-based association study in amyotrophic lateral sclerosis. Brain J. Neurol. 130, 2292-2301.

Kelada, S.N., Shelton, E., Kaufmann, R.B., Khoury, M.J., 2001. Delta-aminolevulinic acid dehydratase genotype and lead toxicity: a HuGE review. Am. J. Epidemiol. 154, 1-13.

Kelada, S.N., Eaton, D.L., Wang, S.S., Rothman, N.R., Khoury, M.J., 2003. The role of genetic polymorphisms in environmental health. Environ. Health Perspect. 111, 1055-1064.

Klaassen, C.D., Liu, J., 1998. Metallothionein transgenic and knock-out mouse models in the study of cadmium toxicity. J. Toxicol. Sci. 23 (Suppl. 2), 97-102.

Krewski, D., Barakat-Haddad, C., Donnan, J., Martino, R., Pringsheim, T., Tremlett, H., van Lieshout, P., Walsh, S.J., Birkett, N.J., Gomes, J., Little, J., Bowen, S., Candundo, H., Chao, T.K., Collins, K., Crispo, J.A.G., Duggan, T., El Sherif, R., Farhat, N., Fortin, Y., Gaskin, J., Gupta, P., Hersi, M., Hu, J., Irvine, B., Jahanfar, S., MacDonald, D., McKay, K., Morrissey, A., Quach, P., Rashid, R., Shin, S., Sikora, L., Tkachuk, S., Taher, M.K., Wang, M.D., Darshan, S., Cashman, N.R., 2017. Determinants of neurological disease: synthesis of systematic reviews. Neurotoxicology 61, 266-289.

Laczmanski, L., Jakubik, M., Bednarek-Tupikowska, G., Rymaszewska, J., Sloka, N., Lwow, F., 2015. Vitamin D receptor gene polymorphisms in Alzheimer's disease patients. Exp. Gerontol. 69, 142-147.

Landers, J.E., Shi, L., Cho, T.J., Glass, J.D., Shaw, C.E., Leigh, P.N., Diekstra, F., Polak, M., Rodriguez-Leyva, I., Niemann, S., Traynor, B.J., McKenna-Yasek, D., Sapp, P.C., AlChalabi, A., Wills, A.M., Brown Jr., R.H., 2008. A common haplotype within the PON1 promoter region is associated with sporadic ALS. Amyotroph. Lateral Scler. 9, 306-314.

Lash, T.L., 2017. The harm done to reproducibility by the culture of null hypothesis significance testing. Am. J. Epidemiol. 186, 627-635.

Lee, Y.H., Kim, J.H., Song, G.G., 2014. Vitamin D receptor polymorphisms and susceptibility to Parkinson's disease and Alzheimer's disease: a meta-analysis. Neurol. Sci. 35, 1947-1953.

Lee, Y.H., Kim, J.H., Seo, Y.H., Choi, S.J., Ji, J.D., Song, G.G., 2015. Paraoxonase 1 Q192R and L55M polymorphisms and susceptibility to amyotrophic lateral sclerosis: a metaanalysis. Neurol. Sci. 36, 11-20.

Li, M., Wang, L., Wang, W., Qi, X.L., Tang, Z.Y., 2014. Mutations in the HFE gene and sporadic amyotrophic lateral sclerosis risk: a meta-analysis of observational studies. Braz. J. Med. Biol. Res, 47, 215-222. 
Lin, M., Zhao, L., Fan, J., Lian, X.G., Ye, J.X., Wu, L., Lin, H., 2012. Association between HFE polymorphisms and susceptibility to Alzheimer's disease: a meta-analysis of 22 studies including 4,365 cases and 8,652 controls. Mol. Biol. Rep. 39, 3089-3095.

Liu, Y., Liu, J., Iszard, M.B., Andrews, G.K., Palmiter, R.D., Klaassen, C.D., 1995. Transgenic mice that overexpress metallothionein-I are protected from cadmium lethality and hepatotoxicity. Toxicol. Appl. Pharmacol. 135, 222-228.

Liu, Y.L., Yang, J., Zheng, J., Liu, D.W., Liu, T., Wang, J.M., Wang, C.N., Wang, M.W., Tian, Q.B., 2012. Paraoxonase 1 polymorphisms L55M and Q192R were not risk factors for Parkinson's disease: a HuGE review and meta-analysis. Gene 501, 188-192.

LoGerfo, A., Chico, L., Borgia, L., Petrozzi, L., Rocchi, A., D'Amelio, A., Carlesi, C., Caldarazzo Ienco, E., Mancuso, M., Siciliano, G., 2014. Lack of association between nuclear factor erythroid-derived 2-like 2 promoter gene polymorphisms and oxidative stress biomarkers in amyotrophic lateral sclerosis patients. Oxidative Med. Cell. Longev. 2014, 432626.

Marchesani, M., Hakkarainen, A., Tuomainen, T.P., Kaikkonen, J., Pukkala, E., Uimari, P., Seppala, E., Matikainen, M., Kallioniemi, O.P., Schleutker, J., Lehtimaki, T., Salonen, J.T., 2003. New paraoxonase 1 polymorphism I102V and the risk of prostate cancer in Finnish men. J. Natl. Cancer Inst. 95, 812-818.

Marzec, J.M., Christie, J.D., Reddy, S.P., Jedlicka, A.E., Vuong, H., Lanken, P.N., Aplenc, R., Yamamoto, T., Yamamoto, M., Cho, H.Y., Kleeberger, S.R., 2007. Functional polymorphisms in the transcription factor NRF2 in humans increase the risk of acute lung injury. FASEB J. 21, 2237-2246.

Menini, T., Gugliucci, A., 2014. Paraoxonase 1 in neurological disorders. Redox Rep. 19, 49-58.

Mitropoulos, K., Merkouri Papadima, E., Xiromerisiou, G., Balasopoulou, A. Charalampidou, K., Galani, V., Zafeiri, K.V., Dardiotis, E., Ralli, S., Deretzi, G., John, A., Kydonopoulou, K., Papadopoulou, E., di Pardo, A., Akcimen, F., Loizedda, A., Dobricic, V., Novakovic, I., Kostic, V.S., Mizzi, C., Peters, B.A., Basak, N., Orru, S., Kiskinis, E., Cooper, D.N., Gerou, S., Drmanac, R., Bartsakoulia, M., Tsermpini, E.E., Hadjigeorgiou, G.M., Ali, B.R., Katsila, T., Patrinos, G.P., 2017. Genomic variants in the FTO gene are associated with sporadic amyotrophic lateral sclerosis in Greek patients. Hum. Genomics 11, 30.

Mollenhauer, B., Locascio, J.J., Schulz-Schaeffer, W., Sixel-Doring, F., Trenkwalder, C. Schlossmacher, M.G., 2011. Alpha-Synuclein and tau concentrations in cerebrospinal fluid of patients presenting with parkinsonism: a cohort study. Lancet Neurol. 10, $230-240$.

Morahan, J.M., Yu, B., Trent, R.J., Pamphlett, R., 2005. Screening the metallothionein III gene in sporadic amyotrophic lateral sclerosis. Amyotroph. Lateral Scler. Other Motor Neuron Disord. 6, 115-117.

Morahan, J.M., Yu, B., Trent, R.J., Pamphlett, R., 2007a. Are metallothionein genes silenced in ALS? Toxicol. Lett. 168, 83-87.

Morahan, J.M., Yu, B., Trent, R.J., Pamphlett, R., 2007b. A gene-environment study of the paraoxonase 1 gene and pesticides in amyotrophic lateral sclerosis. Neurotoxicology 28, 532-540.

Morahan, J.M., Yu, B., Trent, R.J., Pamphlett, R., 2007c. Genetic susceptibility to environmental toxicants in ALS. Am. J. Med. Genet. B Neuropsychiatr. Genet. 144b, 885-890.

Namekata, K., Oyama, F., Imagawa, M., Ihara, Y., 1997. Human transferrin (Tf): a single mutation at codon 570 determines Tf C1 or Tf C2 variant. Hum. Genet. 100, 457-458.

Nandar, W., Neely, E.B., Simmons, Z., Connor, J.R., 2014. H63D HFE genotype accelerates disease progression in animal models of amyotrophic lateral sclerosis. Biochim. Biophys. Acta 1842, 2413-2426.

Neafsey, P., Ginsberg, G., Hattis, D., Sonawane, B., 2009. Genetic polymorphism in cytochrome P450 2D6 (CYP2D6): population distribution of CYP2D6 activity. J. Toxicol. Environ. Health B Crit. Rev. 12, 334-361.

Ng, C.J., Wadleigh, D.J., Gangopadhyay, A., Hama, S., Grijalva, V.R., Navab, M., Fogelman, A.M., Reddy, S.T., 2001. Paraoxonase-2 is a ubiquitously expressed protein with antioxidant properties and is capable of preventing cell-mediated oxidative modification of low density lipoprotein. J. Biol. Chem. 276, 44444-44449.

Nicolas, A., Kenna, K.P., Renton, A.E., Ticozzi, N., Faghri, F., Chia, R., Dominov, J.A., Kenna, B.J., Nalls, M.A., Keagle, P., Rivera, A.M., van Rheenen, W., Murphy, N.A., van Vugt, J., Geiger, J.T., Van der Spek, R.A., Pliner, H.A., Shankaracharya, Smith, B.N., Marangi, G., Topp, S.D., Abramzon, Y., Gkazi, A.S., Eicher, J.D., Kenna, A., Mora, G., Calvo, A., Mazzini, L., Riva, N., Mandrioli, J., Caponnetto, C., Battistini, S., Volanti, P., La Bella, V., Conforti, F.L., Borghero, G., Messina, S., Simone, I.L., Trojsi, F., Salvi, F., Logullo, F.O., D'Alfonso, S., Corrado, L., Capasso, M., Ferrucci, L., Moreno, C.A.M., Kamalakaran, S., Goldstein, D.B., Gitler, A.D., Harris, T., Myers, R.M., Phatnani, H., Musunuri, R.L., Evani, U.S., Abhyankar, A., Zody, M.C., Kaye, J., Finkbeiner, S., Wyman, S.K., LeNail, A., Lima, L., Fraenkel, E., Svendsen, C.N., Thompson, L.M., Van Eyk, J.E., Berry, J.D., Miller, T.M., Kolb, S.J., Cudkowicz, M., Baxi, E., Benatar, M., Taylor, J.P., Rampersaud, E., Wu, G., Wuu, J., Lauria, G., Verde, F., Fogh, I., Tiloca, C., Comi, G.P., Soraru, G., Cereda, C., Corcia, P., Laaksovirta, H., Myllykangas, L., Jansson, L., Valori, M., Ealing, J., Hamdalla, H., Rollinson, S., Pickering-Brown, S., Orrell, R.W., Sidle, K.C., Malaspina, A., Hardy, J., Singleton, A.B., Johnson, J.O., Arepalli, S., Sapp, P.C., McKenna-Yasek, D., Polak, M., Asress, S., Al-Sarraj, S., King, A., Troakes, C., Vance, C., de Belleroche, J., Baas, F., Ten Asbroek, A., Munoz-Blanco, J.L., Hernandez, D.G., Ding, J., Gibbs, J.R., Scholz, S.W., Floeter, M.K., Campbell, R.H., Landi, F., Bowser, R., Pulst, S.M., Ravits, J.M., MacGowan, D.J.L., Kirby, J., Pioro, E.P., Pamphlett, R., Broach, J., Gerhard, G., Dunckley, T.L., Brady, C.B., Kowall, N.W., Troncoso, J.C., Le Ber, I., Mouzat, K., Lumbroso, S., Heiman-Patterson, T.D., Kamel, F., Van Den Bosch, L., Baloh, R.H., Strom, T.M., Meitinger, T., Shatunov, A., Van Eijk, K.R., de Carvalho, M., Kooyman, M., Middelkoop, B., Moisse, M., McLaughlin, R.L., Van Es, M.A., Weber, M., Boylan, K.B., Van Blitterswijk, M., Rademakers, R., Morrison, K.E., Basak, A.N., Mora, J.S., Drory, V.E., Shaw, P.J., Turner, M.R., Talbot, K., Hardiman, O., Williams, K.L., Fifita, J.A.,
Nicholson, G.A., Blair, I.P., Rouleau, G.A., Esteban-Perez, J., Garcia-Redondo, A., AlChalabi, A., Rogaeva, E., Zinman, L., Ostrow, L.W., Maragakis, N.J., Rothstein, J.D., Simmons, Z., Cooper-Knock, J., Brice, A., Goutman, S.A., Feldman, E.L., Gibson, S.B., Taroni, F., Ratti, A., Gellera, C., Van Damme, P., Robberecht, W., Fratta, P., Sabatelli, M., Lunetta, C., Ludolph, A.C., Andersen, P.M., Weishaupt, J.H., Camu, W., Trojanowski, J.Q., Van Deerlin, V.M., Brown Jr., R.H., van den Berg, L.H., Veldink, J.H., Harms, M.B., Glass, J.D., Stone, D.J., Tienari, P., Silani, V., Chio, A., Shaw, C.E., Traynor, B.J., Landers, J.E., 2018. Genome-wide analyses identify KIF5A as a novel ALS gene. Neuron 97 (1268-1283), e1266.

Nie, Y., Luo, D., Yang, M., Wang, Y., Xiong, L., Gao, L., Liu, Y., Liu, H., 2017. A metaanalysis on the relationship of the PON genes and Alzheimer disease. J. Geriatr. Psychiatry Neurol. 30, 303-310.

Niu, M.Y., Wang, L., Xie, A.M., 2015. ApaI, BsmI, FokI, and TaqI polymorphisms in the vitamin D receptor gene and PARKINSON'S disease. Chin. Med. J. 128, 1809-1814.

Paez-Colasante, X., Figueroa-Romero, C., Sakowski, S.A., Goutman, S.A., Feldman, E.L., 2015. Amyotrophic lateral sclerosis: mechanisms and therapeutics in the epigenomic era. Nat. Rev. Neurol. 11, 266-279.

Pasquinelli, A., Chico, L., Pasquali, L., Bisordi, C., Lo Gerfo, A., Fabbrini, M., Petrozzi, L., Marconi, L., Caldarazzo Ienco, E., Mancuso, M., Siciliano, G., 2016. Gly482Ser PGC 1alpha gene polymorphism and exercise-related oxidative stress in amyotrophic lateral sclerosis patients. Front. Cell. Neurosci. 10, 102.

Peters, O.M., Ghasemi, M., Brown Jr., R.H., 2015. Emerging mechanisms of molecular pathology in ALS. J. Clin. Invest. 125, 1767-1779.

Pi, Y., Zhang, L., Chang, K., Li, B., Guo, L., Fang, C., Gao, C., Wang, J., Xiang, J., Li, J., 2012. Lack of an association between Paraoxonase 1 gene polymorphisms (Q192R, L55M) and Alzheimer's disease: a meta-analysis. Neurosci. Lett. 523, 174-179.

Praline, J., Blasco, H., Vourc'h, P., Rat, V., Gendrot, C., Camu, W., Andres, C.R., 2012 Study of the HFE gene common polymorphisms in French patients with sporadic amyotrophic lateral sclerosis. J. Neurol. Sci. 317, 58-61.

Prior, S.L., Clark, A.R., Jones, D.A., Bain, S.C., Hurel, S.J., Humphries, S.E., Stephens, J.W., 2012. Association of the PGC-1alpha rs8192678 variant with microalbuminuria in subjects with type 2 diabetes mellitus. Dis. Markers 32, 363-369.

Qi, Y., Yin, X., Wang, S., Jiang, H., Wang, X., Ren, M., Su, X.P., Lei, S., Feng, H., 2015. PGC-1alpha silencing compounds the perturbation of mitochondrial function caused by mutant SOD1 in skeletal muscle of ALS mouse model. Front. Aging Neurosci. 7, 204.

Reddy, S.T., Wadleigh, D.J., Grijalva, V., Ng, C., Hama, S., Gangopadhyay, A., Shih, D.M., Lusis, A.J., Navab, M., Fogelman, A.M., 2001. Human paraoxonase-3 is an HDL-associated enzyme with biological activity similar to paraoxonase-1 protein but is not regulated by oxidized lipids. Arterioscler. Thromb. Vasc. Biol. 21, 542-547.

Renton, A.E., Chiò, A., Traynor, B.J., 2014. State of play in amyotrophic lateral sclerosis genetics. Nat. Neurosci. 17, 17-23.

Restagno, G., Lombardo, F., Ghiglione, P., Calvo, A., Cocco, E., Sbaiz, L., Mutani, R., Chio, A.H.F.E., 2007. H63D polymorphism is increased in patients with amyotrophic lateral sclerosis of Italian origin. J. Neurol. Neurosurg. Psychiatry 78, 327.

Rhodes, S.L., Buchanan, D.D., Ahmed, I., Taylor, K.D., Loriot, M.A., Sinsheimer, J.S. Bronstein, J.M., Elbaz, A., Mellick, G.D., Rotter, J.I., Ritz, B., 2014. Pooled analysis of iron-related genes in Parkinson's disease: association with transferrin. Neurobiol. Dis. $62,172-178$.

Ricci, C., Battistini, S., Cozzi, L., Benigni, M., Origone, P., Verriello, L., Lunetta, C., Cereda, C., Milani, P., Greco, G., Patrosso, M.C., Causarano, R., Caponnetto, C., Giannini, F., Corbo, M., Penco, S., 2011. Lack of association of PON polymorphisms with sporadic ALS in an Italian population. Neurobiol. Aging 32 (552), e557-513.

Rothman, K.J., 2016. Disengaging from statistical significance. Eur. J. Epidemiol. 31, 443-444.

Rowland, L.P., Shneider, N.A., 2001. Amyotrophic lateral sclerosis. N. Engl. J. Med. 344, 1688-1700.

Sabatelli, M., Marangi, G., Conte, A., Tasca, G., Zollino, M., Lattante, S., 2016. New ALS related genes expand the spectrum paradigm of amyotrophic lateral sclerosis. Brain Pathol. (Zurich, Switzerland) 26, 266-275.

Saeed, M., Siddique, N., Hung, W.Y., Usacheva, E., Liu, E., Sufit, R.L., Heller, S.L., Haines, J.L., Pericak-Vance, M., Siddique, T., 2006. Paraoxonase cluster polymorphisms are associated with sporadic ALS. Neurology 67, 771-776.

Siddons, M.A., Pickering-Brown, S.M., Mann, D.M., Owen, F., Cooper, P.N., 1996 Debrisoquine hydroxylase gene polymorphism frequencies in patients with amyotrophic lateral sclerosis. Neurosci. Lett. 208, 65-68.

Slowik, A., Tomik, B., Wolkow, P.P., Partyka, D., Turaj, W., Malecki, M.T., Pera, J., Dziedzic, T., Szczudlik, A., Figlewicz, D.A., 2006. Paraoxonase gene polymorphisms and sporadic ALS. Neurology 67, 766-770.

Snyder, A.M., Connor, J.R., 2009. Iron, the substantia nigra and related neurological disorders. Biochim. Biophys. Acta 1790, 606-614.

Spisak, K., Klimkowicz-Mrowiec, A., Pera, J., Dziedzic, T., Aleksandra, G., Slowik, A., 2014. rs2070424 of the SOD1 gene is associated with risk of Alzheimer's disease. Neurol. Neurochir. Pol. 48, 342-345.

Su, X.W., Lee, S.Y., Mitchell, R.M., Stephens, H.E., Simmons, Z., Connor, J.R., 2013. H63D HFE polymorphisms are associated with increased disease duration and decreased muscle superoxide dismutase-1 expression in amyotrophic lateral sclerosis patients. Muscle Nerve 48, 242-246.

Su, F.C., Goutman, S.A., Chernyak, S., Mukherjee, B., Callaghan, B.C., Batterman, S., Feldman, E.L., 2016. Association of environmental toxins with amyotrophic lateral sclerosis. JAMA Neurol. 73, 803-811.

Suh, J.K., Poulsen, L.L., Ziegler, D.M., Robertus, J.D., 2000. Redox regulation of yeast flavin-containing monooxygenase. Arch. Biochem. Biophys. 381, 317-322.

Sutedja, N.A., Sinke, R.J., Van Vught, P.W., Van der Linden, M.W., Wokke, J.H., Van Duijn, C.M., Njajou, O.T., Van der Schouw, Y.T., Veldink, J.H., Van den Berg, L.H., 2007. The association between H63D mutations in HFE and amyotrophic lateral 
sclerosis in a Dutch population. Arch. Neurol. 64, 63-67.

Tanaka-Kagawa, T., Jinno, H., Hasegawa, T., Makino, Y., Seko, Y., Hanioka, N., Ando, M., 2003. Functional characterization of two variant human GSTO 1-1s (Ala140Asp and Thr217Asn). Biochem. Biophys. Res. Commun. 301, 516-520.

Taylor, J.P., Brown Jr., R.H., Cleveland, D.W., 2016. Decoding ALS: from genes to mechanism. Nature 539, 197-206.

Thirumoorthy, N., Shyam Sunder, A., Manisenthil Kumar, K.T., Senthil kumar, M., Ganesh, G.N.K., Chatterjee, M., 2011. A review of metallothionein isoforms and their role in pathophysiology. World J. Surg. Oncol. 9, 54.

Trojsi, F., Monsurro, M.R., Tedeschi, G., 2013. Exposure to environmental toxicants and pathogenesis of amyotrophic lateral sclerosis: state of the art and research perspectives. Int. J. Mol. Sci. 14, 15286-15311.

Uversky, V.N., Li, J., Fink, A.L., 2001. Pesticides directly accelerate the rate of alphasynuclein fibril formation: a possible factor in Parkinson's disease. FEBS Lett. 500, 105-108.

Valdmanis, P.N., Kabashi, E., Dyck, A., Hince, P., Lee, J., Dion, P., D'Amour, M., Souchon, F., Bouchard, J.P., Salachas, F., Meininger, V., Andersen, P.M., Camu, W., Dupre, N., Rouleau, G.A., 2008. Association of paraoxonase gene cluster polymorphisms with ALS in France, Quebec, and Sweden. Neurology 71, 514-520.

van Blitterswijk, M., Blokhuis, A., van Es, M.A., van Vught, P.W., Rowicka, P.A. Schelhaas, H.J., van der Kooi, A.J., de Visser, M., Veldink, J.H., van den Berg, L.H., 2012. Rare and common paraoxonase gene variants in amyotrophic lateral sclerosis patients. Neurobiol. Aging 33 (1845), e1841-1843.

Van De Giessen, E., Fogh, I., Gopinath, S., Smith, B., Hu, X., Powell, J., Andersen, P., Nicholson, G., Al Chalabi, A., Shaw, C.E., 2008. Association study on glutathione Stransferase omega 1 and 2 and familial ALS. Amyotroph. Lateral Scler. 9, 81-84.

van Rheenen, W., Diekstra, F.P., van Doormaal, P.T., Seelen, M., Kenna, K., McLaughlin, R., Shatunov, A., Czell, D., van Es, M.A., van Vught, P.W., van Damme, P., Smith, B.N., Waibel, S., Schelhaas, H.J., van der Kooi, A.J., de Visser, M., Weber, M., Robberecht, W., Hardiman, O., Shaw, P.J., Shaw, C.E., Morrison, K.E., Al-Chalabi, A., Andersen, P.M., Ludolph, A.C., Veldink, J.H., van den Berg, L.H., 2013. H63D polymorphism in HFE is not associated with amyotrophic lateral sclerosis. Neurobiol. Aging 34 (1517), e1515-1517.

Vinceti, M., Bottecchi, I., Fan, A., Finkelstein, Y., Mandrioli, J., 2012. Are environmental exposures to selenium, heavy metals, and pesticides risk factors for amyotrophic lateral sclerosis? Rev. Environ. Health 27, 19-41.

Vinceti, M., Mandrioli, J., Borella, P., Michalke, B., Tsatsakis, A., Finkelstein, Y., 2014 Selenium neurotoxicity in humans: bridging laboratory and epidemiologic studies. Toxicol. Lett. 230, 295-303.

Vinceti, M., Filippini, T., Violi, F., Rothman, K.J., Costanzini, S., Malagoli, C., Wise, L.A., Odone, A., Signorelli, C., Iacuzio, L., Arcolin, E., Mandrioli, J., Fini, N., Patti, F., Lo Fermo, S., Pietrini, V., Teggi, S., Ghermandi, G., Scillieri, R., Ledda, C., Mauceri, C., Sciacca, S., Fiore, M., Ferrante, M., 2017a. Pesticide exposure assessed through agricultural crop proximity and risk of amyotrophic lateral sclerosis. Environ. Health $16,91$.

Vinceti, M., Violi, F., Tzatzarakis, M., Mandrioli, J., Malagoli, C., Hatch, E.E., Fini, N., Fasano, A., Rakitskii, V.N., Kalantzi, O.I., Tsatsakis, A., 2017b. Pesticides, polychlorinated biphenyls and polycyclic aromatic hydrocarbons in cerebrospinal fluid of amyotrophic lateral sclerosis patients: a case-control study. Environ. Res. 155, 261-267.

Wakabayashi, K., Yoshimoto, M., Tsuji, S., Takahashi, H., 1998. Alpha-synuclein immunoreactivity in glial cytoplasmic inclusions in multiple system atrophy. Neurosci. Lett. 249, 180-182.

Wang, X.S., Lee, S., Simmons, Z., Boyer, P., Scott, K., Liu, W., Connor, J., 2004. Increased incidence of the Hfe mutation in amyotrophic lateral sclerosis and related cellular consequences. J. Neurol. Sci. 227, 27-33.

Wang, L., Xu, J., Ji, C., Gu, S., Lv, Y., Li, S., Xu, Y., Xie, Y., Mao, Y., 2005. Cloning, expression and characterization of human glutathione S-transferase omega 2. Int. J. Mol. Med. 16, 19-27.

Wang, Y., Xu, S., Liu, Z., Lai, C., Xie, Z., Zhao, C., Wei, Y., Bi, J.Z., 2013. Meta-analysis on the association between the TF gene rs1049296 and AD. The Canadian journal of neurological sciences. J. Can. Sci. Neurol. 40, 691-697.

Wang, Q., Tian, Q., Song, X., Liu, Y., Li, W., 2016. SNCA gene polymorphism may contribute to an increased risk of Alzheimer's disease. J. Clin. Lab. Anal. 30, 1092-1099.

Wasserstein, R.L., Lazar, N.A., 2016. The ASA's statement on p-values: context, process, and purpose. Am. Stat. 70, 129-133.

Wetmur, J.G., 1994. Influence of the common human delta-aminolevulinate dehydratase polymorphism on lead body burden. Environ. Health Perspect. 102 (Suppl. 3), 215-219.

Wills, A.M., Cronin, S., Slowik, A., Kasperaviciute, D., Van Es, M.A., Morahan, J.M. Valdmanis, P.N., Meininger, V., Melki, J., Shaw, C.E., Rouleau, G.A., Fisher, E.M., Shaw, P.J., Morrison, K.E., Pamphlett, R., Van den Berg, L.H., Figlewicz, D.A. Andersen, P.M., Al-Chalabi, A., Hardiman, O., Purcell, S., Landers, J.E., Brown Jr., R.H., 2009. A large-scale international meta-analysis of paraoxonase gene polymorphisms in sporadic ALS. Neurology 73, 16-24.

Xia, J., Xu, H., Jiang, H., Xie, J., 2015. The association between the C282Y and H63D polymorphisms of HFE gene and the risk of Parkinson's disease: a meta-analysis. Neurosci. Lett. 595, 99-103.

Xiromerisiou, G., Dardiotis, E., Tsimourtou, V., Kountra, P.M., Paterakis, K.N., Kapsalaki, E.Z., Fountas, K.N., Hadjigeorgiou, G.M., 2010. Genetic basis of Parkinson disease. Neurosurg. Focus. 28, E7.

Yen, A.A., Simpson, E.P., Henkel, J.S., Beers, D.R., Appel, S.H., 2004. HFE mutations are not strongly associated with sporadic ALS. Neurology 62, 1611-1612.

You, T., Lv, J., Zhou, L., 2013. PON1 Q192R and L55M polymorphisms and organophosphate toxicity risk: a meta-analysis. DNA Cell Biol. 32, 252-259.

Yu, Y., Su, F.-C., Callaghan, B.C., Goutman, S.A., Batterman, S.A., Feldman, E.L., 2014. Environmental risk factors and amyotrophic lateral sclerosis (ALS): a case-control study of ALS in Michigan. PLoS One 9, e101186.

Zaganas, I., Kapetanaki, S., Mastorodemos, V., Kanavouras, K., Colosio, C., Wilks, M.F., Tsatsakis, A.M., 2013. Linking pesticide exposure and dementia: what is the evidence? Toxicology 307, 3-11.

Zarei, S., Carr, K., Reiley, L., Diaz, K., Guerra, O., Altamirano, P.F., Pagani, W., Lodin, D., Orozco, G., Chinea, A., 2015. A comprehensive review of amyotrophic lateral sclerosis. Surg. Neurol. Int. 6, 171.

Zawislak, D., Ostrowska, M., Golenia, A., Marona, M., Tomik, B., Wolkow, P., Gryz-Kurek, E., Szczudlik, A., Slowik, A., 2010. The-A162G polymorphism of the PON1 gene and the risk of sporadic amyotrophic lateral sclerosis. Neurol. Neurochir. Pol. 44, 246-250.

Zhou, S.F., 2009. Polymorphism of human cytochrome P450 2D6 and its clinical significance: part I. Clin. Pharmacokinet. 48, 689-723.

Zintzaras, E., Hadjigeorgiou, G.M., 2004. Association of paraoxonase 1 gene polymorphisms with risk of Parkinson's disease: a meta-analysis. J. Hum. Genet. 49, 474-481.

Zmuda, J.M., Cauley, J.A., Ferrell, R.E., 2000. Molecular epidemiology of vitamin D receptor gene variants. Epidemiol. Rev. 22, 203-217.

Zufiria, M., Gil-Bea, F.J., Fernandez-Torron, R., Poza, J.J., Munoz-Blanco, J.L., RojasGarcia, R., Riancho, J., de Munain, A.L., 2016. ALS: a bucket of genes, environment, metabolism and unknown ingredients. Prog. Neurobiol. 142, 104-129. 